This document is confidential and is proprietary to the American Chemical Society and its authors. Do not copy or disclose without written permission. If you have received this item in error, notify the sender and delete all copies.

\title{
An X-ray and neutron reflectometry study of iron corrosion in seawater
}

\begin{tabular}{|r|l|}
\hline Journal: & Langmuir \\
\hline Manuscript ID & la-2018-00378y.R2 \\
\hline Manuscript Type: & Article \\
\hline Date Submitted by the Author: & $30-$ Apr-2018 \\
\hline Complete List of Authors: & $\begin{array}{l}\text { Wood, Mary; University of Cambridge Department of Chemistry, } \\
\text { Department of Chemistry } \\
\text { Wood, Thomas; STFC, ISIS } \\
\text { Welbourn, Rebecca; ISIS Pulsed Neutron and Muon Source, } \\
\text { Poon, Jeffrey; University of Cambridge Department of Chemistry, } \\
\text { Deparment of Chemistry } \\
\text { Madden, David; University of Cambridge, Department of Chemistry } \\
\text { Clarke, Stuart; University of Cambridge Department of Chemistry, } \\
\text { Department of Chemistry }\end{array}$ \\
\hline
\end{tabular}

SCHOLARONE ${ }^{\text {m }}$

Manuscripts 


\title{
An X-ray and neutron reflectometry study of iron corrosion in seawater
}

Mary H. Wood ${ }^{1 *}$, Thomas J. Wood ${ }^{2}$, Rebecca J. L. Welbourn ${ }^{2}$, Jeffrey Poon ${ }^{1}$, David C. Madden ${ }^{1}$, Stuart M. Clarke ${ }^{1}$

${ }^{1}$ Department of Chemistry, University of Cambridge, Lensfield Road, Cambridge, CB2 1EW, UK

${ }^{2}$ ISIS Neutron \& Muon Source, Rutherford Appleton Laboratory, Didcot, OX11 0QX, UK

*maryhwood@gmail.com

\begin{abstract}
The corrosive breakdown of thin iron films supported on silicon substrates under a number of conditions is presented-in particular to understand better how iron, and hence ferritic steel, behaves in a salty water environment. A combination of X-ray and neutron reflectometry was used to monitor the structures of both the metal and oxide surface layers and also organic corrosion inhibitors adsorbed at the iron/aqueous interface.
\end{abstract}

A range of behaviour in seawater was observed, including complete dissolution and void formation under the metal surface. Importantly, two simple treatments-UV/ozone or soaking in ultrapure water-were found to significantly protect the iron surface for considerable lengths of time, although evidence of pitting corrosion began after around 10 days. The underlying causes of the efficacies of these treatments were further investigated using X-ray photoelectron spectroscopy.

In addition, three potential corrosion inhibitors were investigated: (i) dodecyltrimethylammonium bromide (DTAB) demonstrated no ability to protect the surface; (ii) sodium dodecyl sulfate (SDS) appeared to accelerate corrosion; (iii) bis(2-ethylhexyl)phosphate showed an impressive level of protection (the neutron reflectometry results indicated a thick diffuse layer of surfactant of $23 \%$ surface coverage). These findings have been interpreted in terms of preferential inhibitor adsorption at cathodic and anodic surface sites (depending on the nature of the inhibitor).

\section{Introduction}

The extraordinarily high cost of corrosion to the world economy is inescapable, coming in at an estimated 3-4 \% of the GDP of industrialised nations ${ }^{1,2}$. Whilst it has been a key topic for scientific research for many years, the complexity of corroding systems, which typically involve a whole range of metal, oxide, hydroxide and dissolved species, has meant corrosion remains a problem essentially without a solution. The theoretical background of corrosion is well-documented in the literature $\mathrm{e}^{3-5}$; briefly, anodic and cathodic areas exist on a metal surface exposed to a corrosive environment and form an electrochemical cell in the solution. The anodic reaction involves oxidation of the metal-for example, in the case of iron:

$$
\mathrm{Fe}_{(s)} \rightarrow \mathrm{Fe}_{(a q)}^{2+}+2 e^{-}
$$

Various complementary cathodic reactions are possible, including:

$$
\begin{gathered}
\mathrm{O}_{2}+2 \mathrm{H}_{2} \mathrm{O}+4 e^{-} \rightarrow 4 \mathrm{OH}^{-} \\
2 \mathrm{H}^{+}+2 e^{-} \rightarrow \mathrm{H}_{2}
\end{gathered}
$$


Salty solutions such as those found in seawater are well-known to be highly corrosive; in particular, the chloride ion is extremely aggressive towards iron and other metal surfaces. The reason behind this probably arises from a number of causes, not least that the formation of the soluble $\mathrm{FeCl}_{2}$ complex at the anode will pull the dissolving iron into solution and prevent it reprecipitating ${ }^{6}$. Metals capable of forming a 'passive' oxide film at the surface that provides some resistance to homogeneous uniform corrosion are typically more prone to the formation of localised pits that can be extremely detrimental, particularly given the difficulty associated with either predicting them or locating them once formed ${ }^{7}$.

Whilst the oxide film that forms at the iron surface is often referred to as 'passive', this is not strictly accurate-although it is able to offer resistance to corrosion in some environments, it is still relatively easily broken down in chloride-containing solutions. The exact mechanism by which chloride ions interact with the oxide film to initiate pitting corrosion has been unresolved for many decades $^{6-10}$. A selection of mechanisms have been proposed, the most prevalent being adsorption, film breakdown and penetration. Briefly, the adsorption mechanism assumes preferential chloride adsorption at the oxide surface, displacing oxygen anions and catalysing the stripping of Fe ${ }^{\text {III }}$ ions via formation of $\mathrm{FeOCl}$ complexes ${ }^{3}$. This is presumed to lead to greatly accelerated thinning of the passive film localised at positions where the chloride ions have adsorbed ${ }^{11}$. Kinetic measurements on a stainless steel surface indicate that the halide ions adsorb in groups of 3 or 4 to form a soluble complex around a surface cation, which is then immediately pulled into solution ${ }^{12}$.

The film breakdown mechanism assumes that pitting arises due to local cracks or defects in the oxide film where the bare metal is exposed to the electrolyte. These areas should be able to repassivate in solution, but, in the presence of aggressive anions, corrosion will occur at a higher rate than the repassivation and hence lead to pit formation. Due to the poor lattice match of iron oxide to the underlying metal, the likelihood of crack formation is thought to increase for oxide layers above a critical thickness due to internal stresses. It is also thought that the adsorption of the chloride ions may cause peptisation due to repulsion of the charged complexes, leading to cracks forming in the oxide film ${ }^{13-17}$.

The penetration mechanism proposes diffusion of chloride anions through the oxide film to the metal/oxide interface, where they then accelerate dissolution of the metal. They are thought to travel across the oxide layer via dislocations that allow the passage of complexing water molecules ${ }^{10}$. Numerous studies have been conducted in an effort to detect chloride ions within the oxide film (and particularly at the metal/oxide interface), with apparent evidence available in abundance for both their presence and absence. Although several papers present depth-profiling XPS, Auger and SIMS data showing chloride penetration throughout the oxide film ${ }^{13,18-22}$, others demonstrate that these techniques often also show the presence of chloride in control samples and suggest that they may be an artefact of the technique ${ }^{23}$; alternatively, it has been suggested sample preparation is key, since the oxide film is often grown within a chloride-containing solution ${ }^{24-26}$. Strehblow raises the 
issue that pit nucleation times (of < $1 \mathrm{~s}$ in some instances) are often shorter than the time expected for aggressive anions to diffuse across the passive layer, indicating instead that their main activity may lie at local defect sites ${ }^{27}$.

The passive oxide film that forms on iron surfaces has long been the subject of study, and is not simple in structure or composition. Whilst the exact nature of the passive layer may depend on the precise sample in question (preparation, environmental exposure etc.), it is normally found to comprise a mixture of oxides and hydroxides, most commonly hematite $\left(\mathrm{Fe}_{2} \mathrm{O}_{3}\right)$ and magnetite $\left(\mathrm{Fe}_{3} \mathrm{O}_{4}\right)$. Nagayama et al. model the oxide layer formed on iron upon oxidation in air as comprising $\mathrm{Fe}_{3} \mathrm{O}_{4}$ initially, of which the outer part is gradually oxidised to form $\mathrm{\gamma}-\mathrm{Fe}_{2} \mathrm{O}_{3}$ (maghemite); the outermost part of this is further oxidised to form a thin layer that appears to adopt a 'vacancy' structure depleted in iron ${ }^{28}$. Polarised neutron reflectometry (PNR) data measured for iron films has found the oxide film to be partially magnetic, suggesting a mixture between magnetite (magnetic)

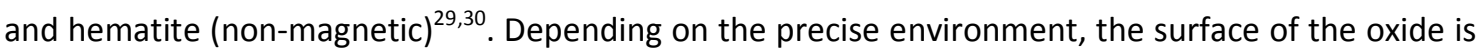
often covered with a hydroxide film; Haupt et al. used a combination of angular-dependent XPS and electrochemical methods to characterise this outermost layer as comprising a mixture of FeO and $\mathrm{Fe}(\mathrm{OH})_{2}$ when the surface is exposed to an alkaline electrolyte ${ }^{31}$. Cahan et al. link the penetration of protons into the passive film, and hence increasing concentration of Fe" ions as opposed to Fe" , to the likelihood of the film dissolving, as Fe" has a much higher solubility ${ }^{32}$. Foley et al .reported that it is the outer $\mathrm{\gamma}-\mathrm{Fe}_{2} \mathrm{O}_{3}$ in the oxide film that is 'passive' against corrosion, whereas the $\mathrm{Fe}_{3} \mathrm{O}_{4}$ content is more vulnerable to attack, presumably due to the increased Fe" content ${ }^{33}$.

Whilst many surface treatments exist to protect iron and related surfaces against corrosion, it is difficult to completely prevent any crack or defect and hence the potential formation of pits; to this end, corrosion inhibitors may be added that adsorb to the surface preferentially, displacing any aggressive species and hence passivating the metal surface ${ }^{19}$. An advantage of using inhibitors is that they can compete with corroding species to readsorb to surfaces after corrosion has started, whereas metals may struggle to repassivate after breakdown of the oxide film. It has been shown that effective corrosion inhibition is achieved at much less than full surface coverage, since the inhibitors-often organic species-adsorb firstly to active sites on the surface that are particularly prone to corrosion; the remaining surface sites are generally extremely slow to corrode in comparison $^{34-37}$.

Traditional methods of corrosion study are often physical-e.g. weight loss tests-or electrochemical-e.g. electrochemical impedance spectroscopy (EIS). Whilst these certainly have great advantages (for example, electrochemical methods often allow a simple way of quantifying the corrosion of each system), they are limited in the extent to which they can provide fundamental structural information about the corroding interface. Techniques such as X-ray photoelectron spectroscopy (XPS) ${ }^{38,39}$ have been used to better understand the surface chemistry of corroding 
surfaces, and whilst these are mainly ex situ, the increasing popularity of new near-ambient XPS techniques makes this a promising tool for future study in this area.

In this work, the main techniques used were X-ray reflectometry (XRR) and neutron reflectometry $(\mathrm{NR})$, both of which give approximately angstrom-level definition of film thicknesses (inversely proportional to the spacing of the characteristic Kiessig fringes), roughnesses and composition in the z-direction (perpendicular to the surface plane).

Whilst both XRR and NR are extremely powerful in characterising the structural features of corrosive systems at the angstrom-scale, they remain relatively untapped techniques in this area ${ }^{40}$. A few studies also exist pertaining to the use of X-rays in this area-for example, Springell et al. combined XRR with X-ray diffraction (XRD) to monitor the corrosion and accompanying changes in density of uranium oxide layers on uranium samples, uncovering buried changes that would have been difficult to measure by other techniques ${ }^{41}$.

In this work, iron films deposited on silicon substrates were subjected to varying corrosive environments with the aim of discovering how the iron and oxide layers respond to exposure to high-salt solutions, chosen to mimic natural seawater. XRR and NR were combined to measure the changes in metal/oxide and adsorbed surfactant structures (when potential corrosion inhibitors were added) respectively. Other promising anti-corrosion treatments were also discovered serendipitously, as discussed below.

\section{Experimental}

\begin{tabular}{|c|c|c|c|}
\hline & $\begin{array}{c}\text { Concentration / } \\
\mathbf{g ~ L}^{-1}\end{array}$ & $\begin{array}{c}\text { Concentration / } \\
\mathrm{mg} \mathrm{m}^{-1}\end{array}$ \\
\hline $\mathrm{Cl}^{-}$ & 19.29 & $\mathrm{Ca}^{2+}$ & 0.40 \\
\hline $\mathrm{Na}^{+}$ & 10.78 & $\mathrm{CO}_{3}{ }^{2-}$ & 0.20 \\
\hline $\mathrm{SO}_{4}{ }^{2-}$ & 2.66 & $\mathrm{Br}^{-}$ & 0.06 \\
\hline $\mathrm{Mg}^{2+}$ & 1.32 & Others & $<0.01$ \\
\hline $\mathrm{K}^{+}$ & 0.42 & & \\
\hline
\end{tabular}

Table 1. Concentrations of salts used in model seawater, from Sigma-Aldrich sea salts.

\section{Materials}

Iron films (10-20 nm thickness) were deposited onto polished silicon substrates, (111)-orientation, (n)-type, using electron-beam deposition in vacuo at the Nanoscience Centre at the University of Cambridge. All chemicals were purchased from Sigma-Aldrich and used without further purification (purities $>99 \%$ as determined by GC and/or titration). Model seawater (aerated) was prepared from the standard sea salts provided by Sigma-Aldrich, with a salt composition comparable to that used throughout the literature ${ }^{42,43}$, as detailed in Table 1 . The concentration of the surfactant solutions 
was $5 \mathrm{mM}$ other than for bis(2-ethylhexyl)phosphate, where a saturated solution was used (solubility in water is $0.56 \mathrm{mM}$ ).

\section{$X R R$}

XRR profiles were collected at the Cavendish Laboratory, Cambridge using a Bruker D8 X-ray diffractometer with copper target (wavelength $1.54 \AA$ ) and a Goebel mirror. An accelerating voltage of $50 \mathrm{kV}$ was used and a primary beam size of $0.1 \mathrm{~mm}$. $0.35 \mathrm{~mm}$ soller slits were inserted before the detector, which was operated in 1D mode. XRR scans were run in 2 $\theta / \omega$ mode and data were fitted using GenX 2.0.0 software ${ }^{44}$. Iron films were measured as-received, and then following exposure to the solution of interest. The iron film/silicon substrates were mainly large blocks (100 $\mathrm{mm} \times 80 \mathrm{~mm} \times$ $15 \mathrm{~mm}$ ) clamped into a custom-made PTFE trough, although measurements were also taken of smaller pieces $(10 \mathrm{~mm} \times 10 \mathrm{~mm} \times 1 \mathrm{~mm})$ left soaking in solutions in open air for comparison, as detailed in the results section. The substrates were removed from the solution and allowed to dry before each measurement. Uncertainties were calculated from a bespoke bootstrapping procedure (see Supporting Information).

\section{$X P S$}

XPS measurements were taken at the NEXUS laboratory in Newcastle using the AXIS Nova XPS spectrometer equipped with a monochromatic Al-K $\alpha$ X-ray source. Small silicon wafers (10 mm x 10 $\mathrm{mm} \times 1 \mathrm{~mm}$ ) were coated with the iron films and measured as-received, after UV/ozone treatment (30 minutes) or after soaking in ultrapure water $(18.2 \mathrm{M} \Omega \mathrm{cm}, 1 \mathrm{~h})$. Spectra were fitted using the CasaXPS software using a Shirley background and calibrated by setting the C 1s peak to $285.0 \mathrm{eV}$.

$N R$

Neutron reflectometry data were collected using the OFFSPEC instrument at the ISIS neutron facility, Rutherford Appleton Laboratory, UK. Full details of the instrument may be found elsewhere ${ }^{45}$. The instrument was used in non-polarised mode, and a magnetic field was applied to the samples to prevent any potential effects of domain scatter. Data were collected at scattering angles of $0.5^{\circ}, 1.0^{\circ}$ and $2.0^{\circ}$. Silicon substrates $(100 \times 80 \times 15 \mathrm{~mm})$ coated with an iron film were cleaned by UV/ozone (30 minutes) before being mounted in a custom-made aluminium cell with a PTFE trough. The footprint was controlled to only illuminate the surface region within the trough. The bare substrates were characterised in $\mathrm{D}_{2} \mathrm{O}, \mathrm{H}_{2} \mathrm{O}$ and CMSi (a 38:62 mixture of $\mathrm{D}_{2} \mathrm{O}$ and $\mathrm{H}_{2} \mathrm{O}$ to contrast-match to the silicon). The solution of interest (seawater or a surfactant dissolved in seawater) was then pumped in via HPLC syringe pump and measurements taken immediately at the middle angle $\left(1.0^{\circ}\right)$, as the greatest changes in reflectivity would be expected in this region. A full set of data (with a measurement time of 2 hours) was then collected across all angles, compared to that initially taken at $1.0^{\circ}$ and added together if no difference was seen. The sample exposed to seawater alone was removed from the sample cell after 15 hours and allowed to dry before being resubmerged in seawater exposed to the atmosphere for 4 hours and then resealed in the NR sample cell to ensure lack of oxygen was not preventing corrosion, as detailed in the results section. Fitting of the NR data 
was also executed using the GenX 2.0.0 software; the model averaged the intensities from up- and down-spin states, using the assumption that the magnetic domain size was larger than the coherence length of the beam.

\section{Results and Discussion}

(1) Corrosion in untreated seawater.
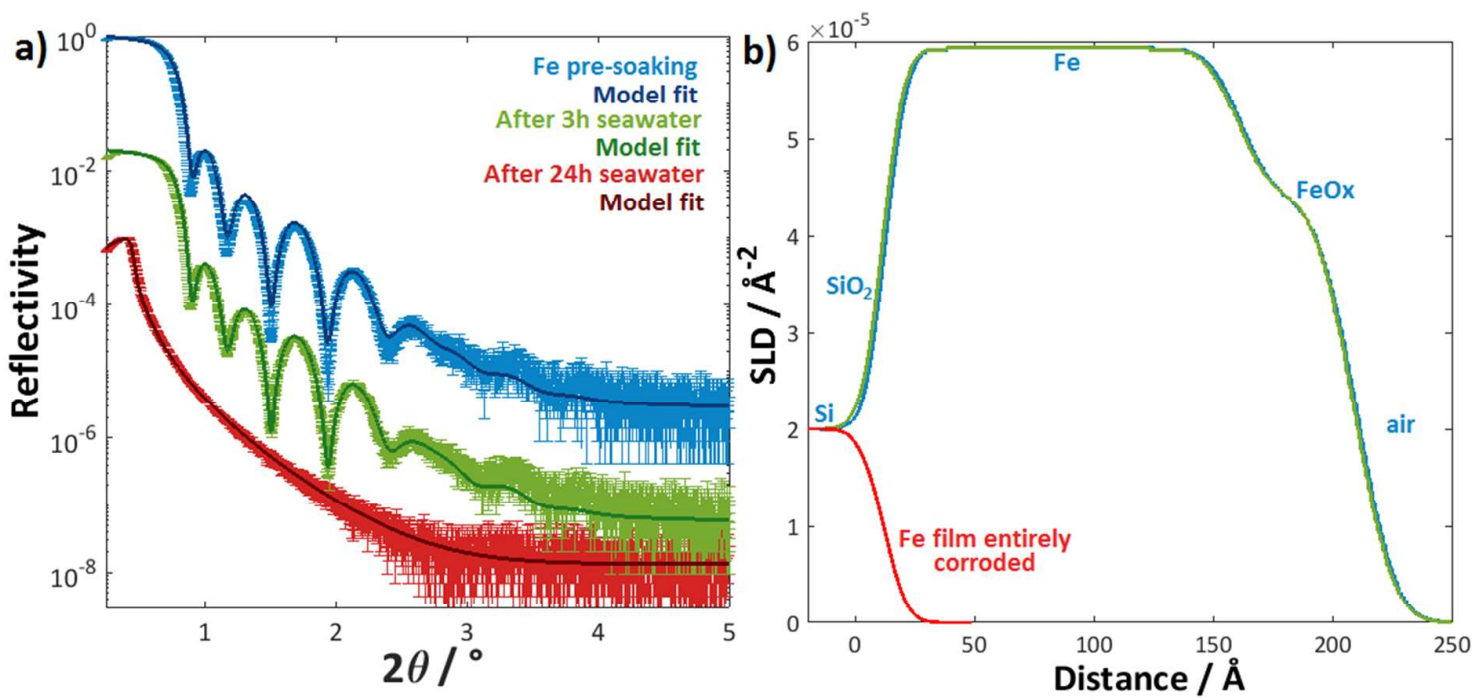

Figure 1a) XRR data (points) and model fits (solid lines) for iron film pre-soaking and post-soaking in seawater after 3 and $24 \mathrm{~h}$, as labelled. Data offset vertically for clarity. b) Scattering length density (SLD) profiles of the model fits (real and imaginary).

\begin{tabular}{|c|c|c|c|c|}
\hline & & \multicolumn{3}{|c|}{ Thickness / $\AA$} \\
\hline & $\begin{array}{c}\text { Density } \\
\text { / f.u. } \AA^{-3}\end{array}$ & Bare Fe film & $\begin{array}{c}\text { After 3 h } \\
\text { seawater }\end{array}$ & $\begin{array}{c}\text { After 24 h } \\
\text { seawater }\end{array}$ \\
\hline $\mathrm{SiO}_{2}$ & 0.0220 & 12 & 12 & 9 \\
\hline Fe & 0.0850 & 150 & 149 & 0 \\
\hline Fe oxide & 0.0212 & 45 & 39 & 0 \\
\hline Hydroxide & 0.0103 & 13 & 14 & 0 \\
\hline
\end{tabular}

Table 2. Fitted parameters for the bare iron film and after exposure to seawater (fixed parameters in italics). The units used for the density are those used by the GenX fitting software. The thickness values are modelled to an accuracy of +3 Å.

Representative XRR data for an iron film soaked in seawater is displayed in Figure 1, with model fits included. The bare iron film was modelled using three layers-pure iron, an iron oxide layer and a thin iron hydroxide layer on top, as summarised in $\mathrm{Table}^{2}$. An $\mathrm{SiO}_{2}$ layer was also included to capture the native oxide. The densities of the $\mathrm{SiO}_{2}$ and Fe layers were kept fixed at the expected bulk values, whilst those for the oxide and hydroxide films were fitted, as their exact composition was not known in advance; furthermore, it seemed likely that their average densities might change upon exposure to the corrosive seawater due to formations of voids or cavities. The initial thickness of the iron film (150.0 ̊̊) was in good agreement with that expected from the deposition process. 
The fitted scattering length density (SLD) profiles shown in Figure $1 \mathrm{~b}$ demonstrate that there is little change (within uncertainties) to the sample after $3 \mathrm{~h}$ soaking. However, the entire film is essentially dissolved after $24 \mathrm{~h}$, as clearly shown by the loss of fringes in Figure 1a. (It should be noted that the high level of roughness in the fully corroded samples makes any conclusions about exactly how much material remains on the sample difficult, due to greater levels of diffuse scattering; however, it is clear that the vast extent of the original metal film has been destroyed). Interestingly, visual inspection of the film after $3 \mathrm{~h}$ showed some evidence of localised corrosion (Figure $\mathrm{S} 1$ ) that is not picked up by the XRR technique; this is because the reflection technique measures composition averaged across the whole sample and hence localised changes may not give a significant variation overall. Additional samples soaked in seawater left in open air showed the same trends, demonstrating that the process of sealing the film in a cell had little or no effect on the corrosion process.
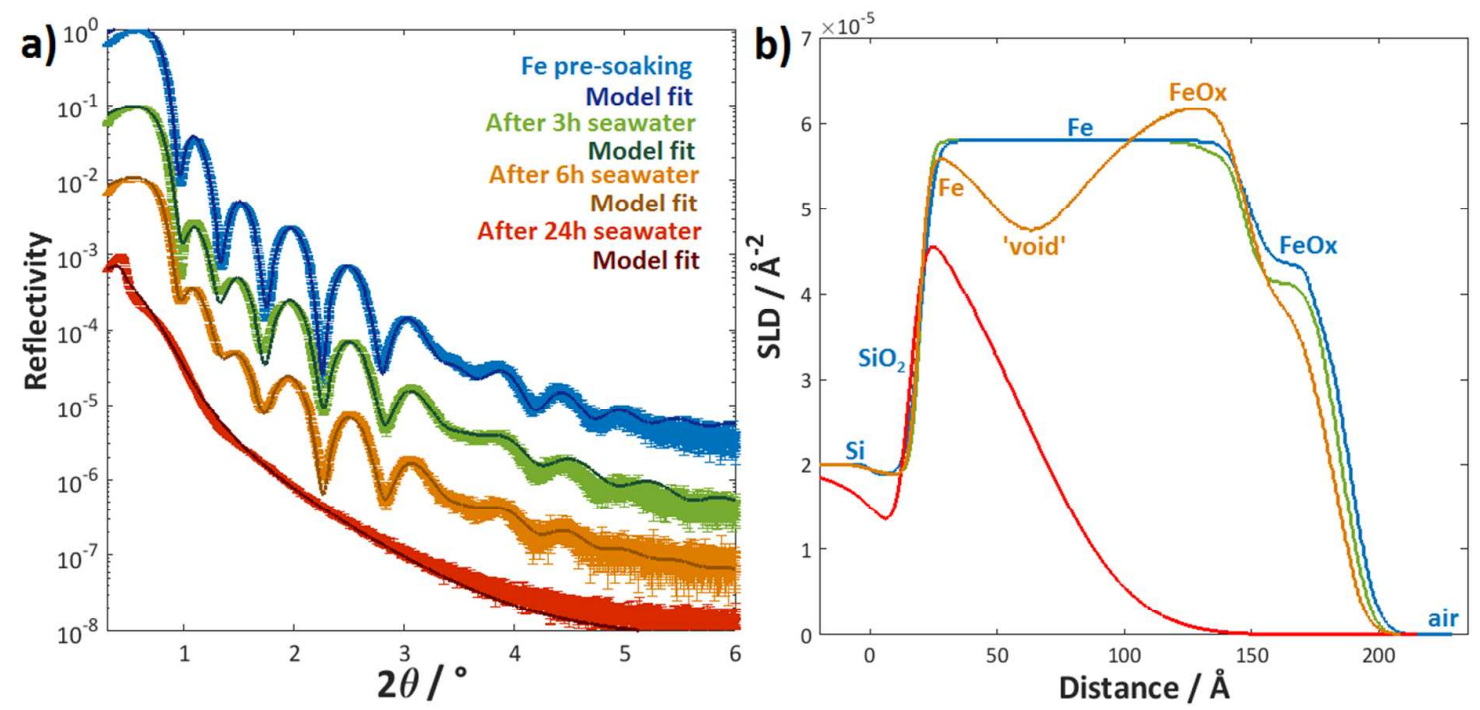

Figure 2. a) XRR data (points) and model fits (solid lines) for a bare iron film as-deposited and after soaking in seawater for $3 \mathrm{~h}, 6 \mathrm{~h}$ and $24 \mathrm{~h}$ as labelled. Data offset vertically for clarity. b) SLD profiles for the model fits. 

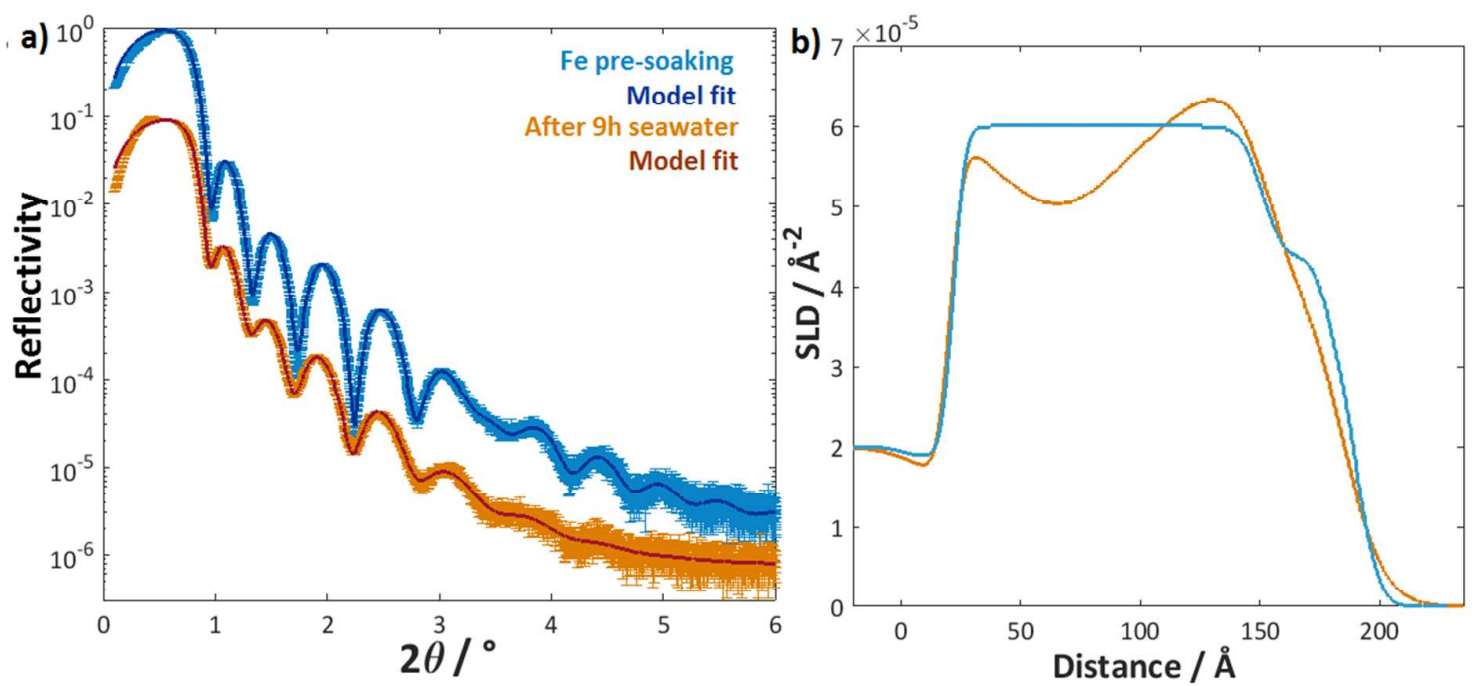

Figure 3a) XRR data (points) and model fits (solid lines) for a bare iron film as-deposited and after soaking in seawater for $9 \mathrm{~h}$ as labelled. Data offset vertically for clarity. b) SLD profiles for the model fits.
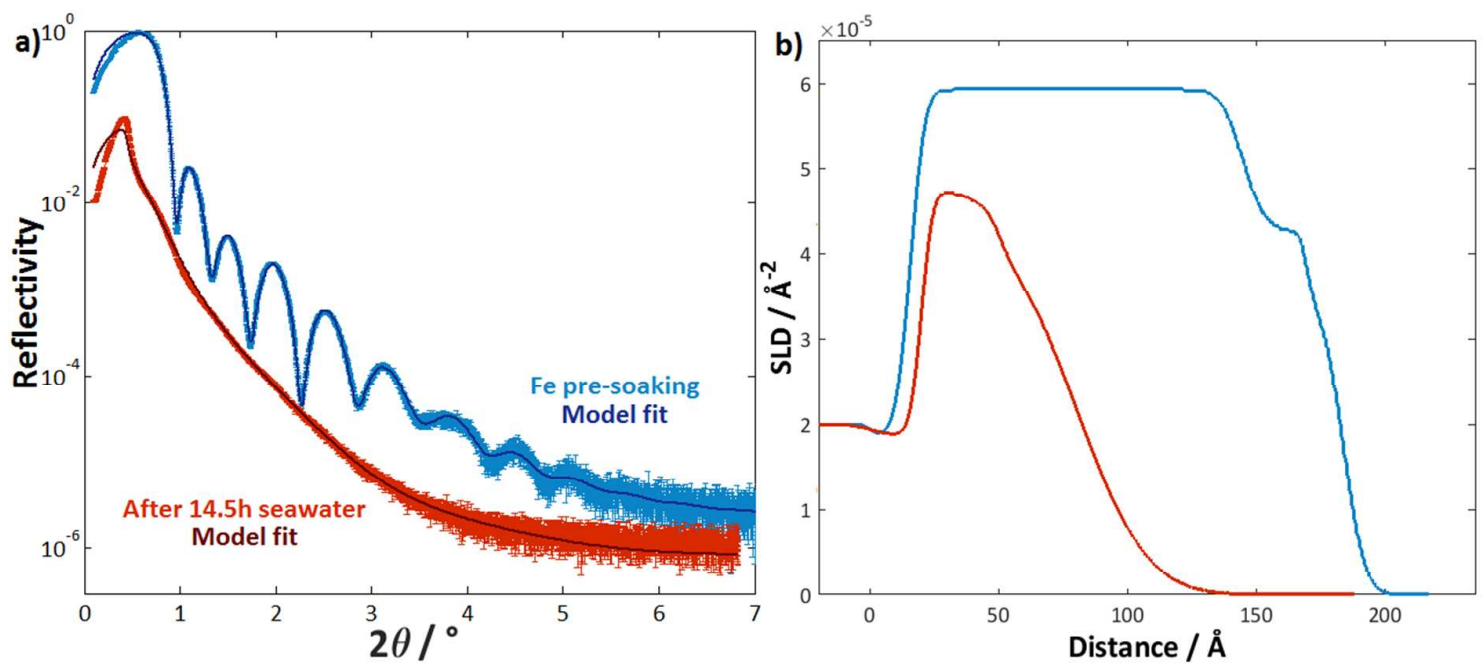

Figure 4a) XRR data (points) and model fits (solid lines) for a bare iron film as-deposited and after soaking in seawater for $\mathbf{1 4 . 5} \mathrm{h}$, as labelled. Data offset vertically for clarity. b) SLD profiles for the model fits.

In an attempt to get a more detailed breakdown of the corrosion process between $3 \mathrm{~h}$ and $24 \mathrm{~h}$, three further identical samples were soaked in seawater for varying time increments, with the XRR data and model fits shown in Figure 2-Figure 4. The most immediate observation is that there is significant variation in the rate of corrosion between samples, as might be expected from the wellestablished difficulty in predicting corrosion and pit formation. For example, the model fit shown in Figure 1 for the sample after $3 \mathrm{~h}$ seawater indicated essentially no change in iron or oxide layers, whereas for the sample shown in Figure 2, the only way to model the experimental data was by a loss of around $18 \AA$ iron, and around $20 \AA$ oxide (see Table S1 for fits and uncertainties derived from the bootstrapping procedure).

After $6 \mathrm{~h}$ exposure to seawater, there is evidence of a void growing under the iron film, seen by a dip in the SLD profile (Figure $2 \mathrm{~b}$ ), and it was necessary to include a more gradual variation in the SLD 
than for the simple few-block model. The sample soaked for $9 \mathrm{~h}$ (Figure 3) showed a similar underlying void, although to a lesser extent than at $6 \mathrm{~h}$-this is most probably due to slight variations in the samples; even though both were prepared at the same time in identical fashion, even minor differences in the density of surface active sites may cause significant variation in the propagation rates of pitting corrosion ${ }^{46,47}$. Singh et al. have previously seen a similar void-growth behaviour for nickel films in acidic chloride solutions using neutron reflectometry ${ }^{48}$; reflectometry techniques clearly offer an opportunity to monitor such structural changes that would be very difficult to observe otherwise.

Interestingly, the fits for the corroding samples necessitated inclusion of a high-SLD layer at the surface, arising from an increase in density of the oxide film. This may be an artefact of the fitting process, due to the high layer roughnesses as corrosion progresses, or may be an indication of iron diffusion towards the surface.

However, it is clear that by $15-24 \mathrm{~h}$, the entire iron film has broken down in all cases, with only a small, extremely rough layer remaining. This corresponds to a yearly dissolution of around $10 \mu \mathrm{m}$, which is relatively low; normally, levels of $<0.05 \mathrm{~mm}_{\text {year }}{ }^{-1}$ are considered satisfactory, a factor of 5 greater than that seen for the iron samples here ${ }^{49}$. However, the propagation of pits such as those seen for one of the samples may lead to accelerated corrosion and catastrophic breakdown of the iron surface; certainly, the rate of corrosion is seen to increase over time for all the samples, with the bulk of dissolution occurring between 9 and $24 \mathrm{~h}$. It is also worth noting that the nature of the thin films used in this work may differ slightly in their response to corrosive solutions compared to the bulk substrate in terms of stresses across the film etc. However, no evidence of delamination from the underlying silicon was seen as the 'voids' were not directly at the silicon/iron interface.
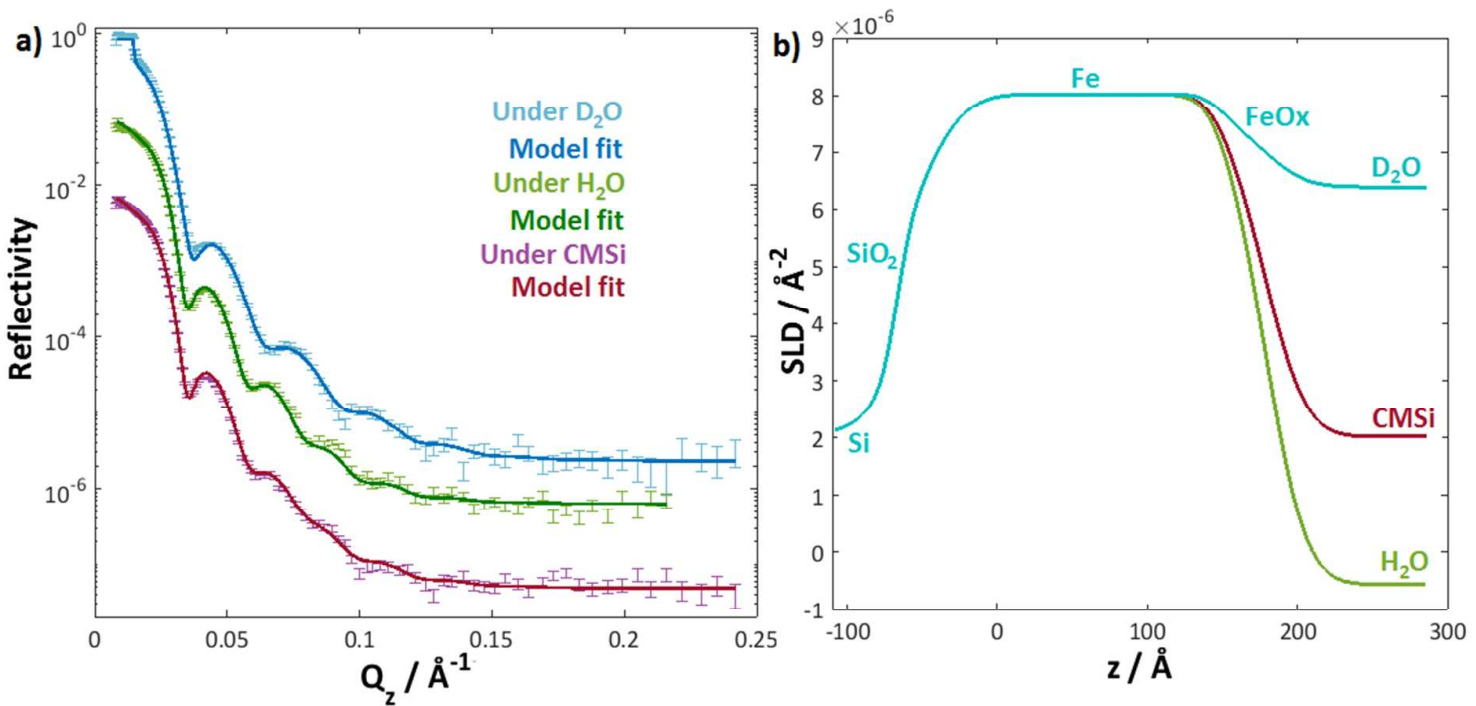

Figure 5 a) NR data (points) and model fits (solid lines) for an iron film as-deposited under three different water contrasts, as labelled (CMSi = contrast-matched to silicon). Data offset vertically for clarity. b) SLD profiles for the model fits. 


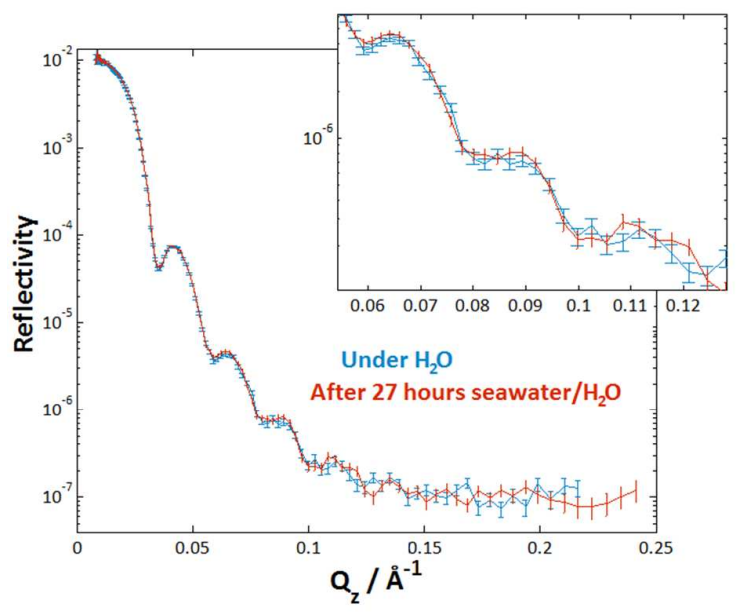

Figure 6. NR data for iron film in pure $\mathrm{H}_{2} \mathrm{O}$ (blue) and after $27 \mathrm{~h}$ soaking in seawater/ $\mathrm{H}_{2} \mathrm{O}$, with enlarged central section shown in inset.

NR data for a bare iron film in the three water contrasts is shown in Figure 5a with the SLD profiles of the model fits shown in Figure $5 b$. The iron layer was modelled to be $205 \AA$ ( $\pm 3 \AA$ ) thick, in good agreement with the expected deposition thickness, with an oxide layer $29 \AA$ ( $\pm 3 \AA$ ) thick. Following characterisation, the neutron cell was filled with seawater $/ \mathrm{H}_{2} \mathrm{O}$ with a large volume being pushed through to ensure complete exchange. Neutron reflectivity profiles were subsequently recorded after every $2 \mathrm{~h}$ in order to fully characterise the corrosion process.

However, in a departure from the XRR results, which showed that most of the film was dissolved after $15 \mathrm{~h}$, no change was seen in the neutron data at all after this time. To ensure the corrosion was not being prevented by lack of oxygen, air was pushed through the cell for several minutes before being refilled with seawater. As the subsequent profile again showed no change, the sample was then removed and allowed to stand in seawater left in the open air for 4 hours, before being resealed in the cell and remeasured over $2 \mathrm{~h}$ intervals; after $27 \mathrm{~h}$, at the end of the experiment, the data still showed essentially no change (Figure 6).

As this result was in stark contrast to the XRR data, it is clear that there must be some additional effect causing the different samples to corrode at very different rates. Given that the act of sealing or not sealing the sample in a cell had already been found to have no effect on the corrosion rate, only two differences in sample treatment remained:

(i) First, the samples for neutron analysis were cleaned using UV/ozone cleaning for 30 minutes before analysis (to ensure the removal of any adventitious organic contamination that would complicate the neutron data).

(ii) Secondly, in order to characterise the bare iron films, they were firstly measured in ultrapure water $\left(\mathrm{H}_{2} \mathrm{O}, \mathrm{D}_{2} \mathrm{O}\right.$ and $\mathrm{CMSi}-\mathrm{i}$.e. water with SLD contrast-matched to that of silicon), whereas the samples used for XRR were placed directly into the seawater without firstly being exposed to ultrapure water ('UPW'). 
In order to verify the effects of either or both of these experimental steps on the corrosion rate of the iron substrates, further samples were separately treated by UV/ozone or pre-soaked in UPW before being subjected to seawater and characterised by XRR over time, as detailed below.

(i) Effect of UV/ozone
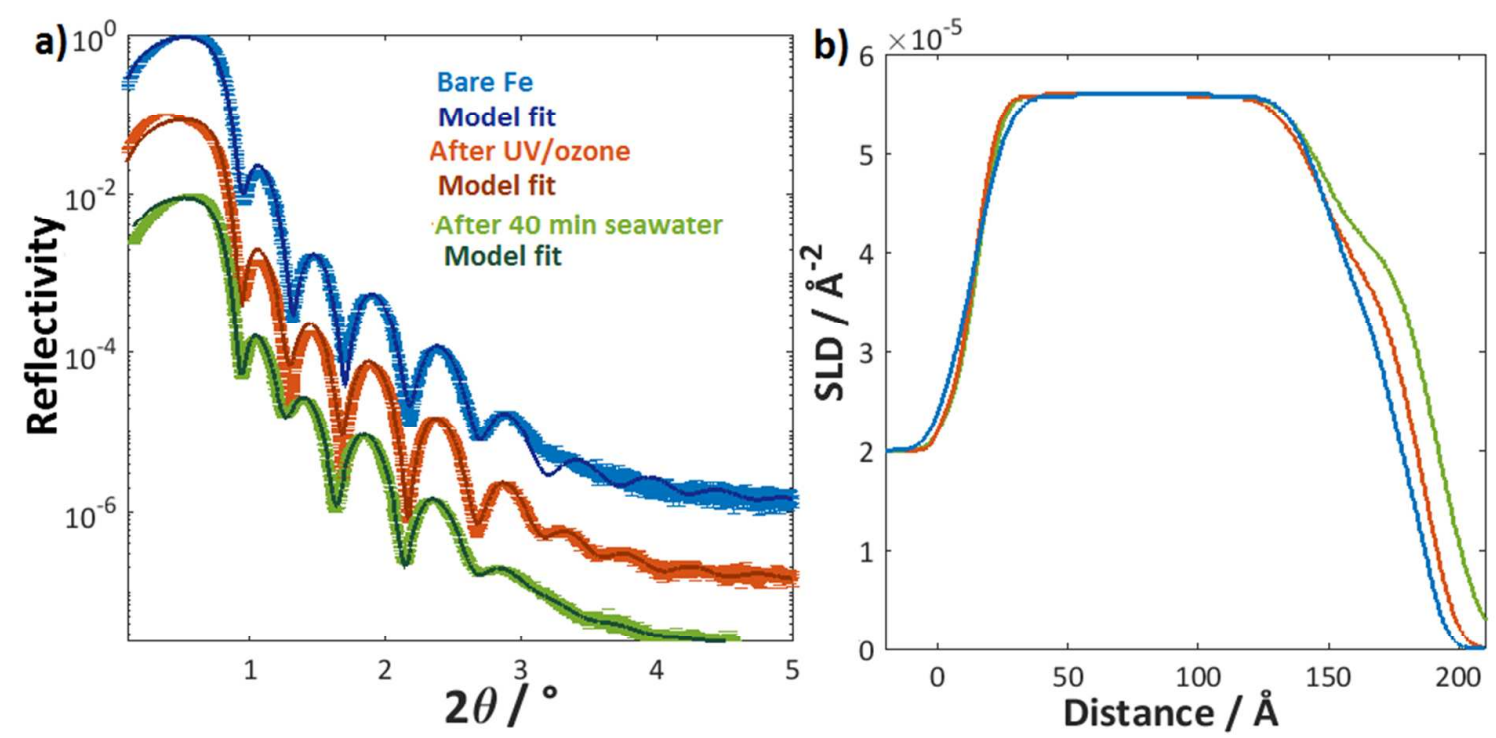

Figure 7a) XRR data (points) and model fits (solid lines) for an iron film as received, after cleaning with UV/ozone for 1 h and after $\mathbf{4 0}$ minutes of soaking in seawater, as labelled. (Data offset vertically for clarity). b) SLD profiles for the model fits.

Figure 7 shows the XRR data and model fits for an iron sample as-deposited, after cleaning with UV/ozone and following subsequent soaking in seawater for 40 minutes. Unsurprisingly, an increase in thickness for the oxide layer is seen after $1 \mathrm{~h} \mathrm{UV/ozone} \mathrm{cleaning,} \mathrm{albeit} \mathrm{a} \mathrm{modest} \mathrm{one} \mathrm{of} 6 \AA$. After 40 minutes of seawater, a further increase in oxide thickness is seen, accompanied by a small dissolution of the underlying iron layer (of $3 \AA$ ) ; the roughness of each layer also increases to $10-11$ $\AA$. 

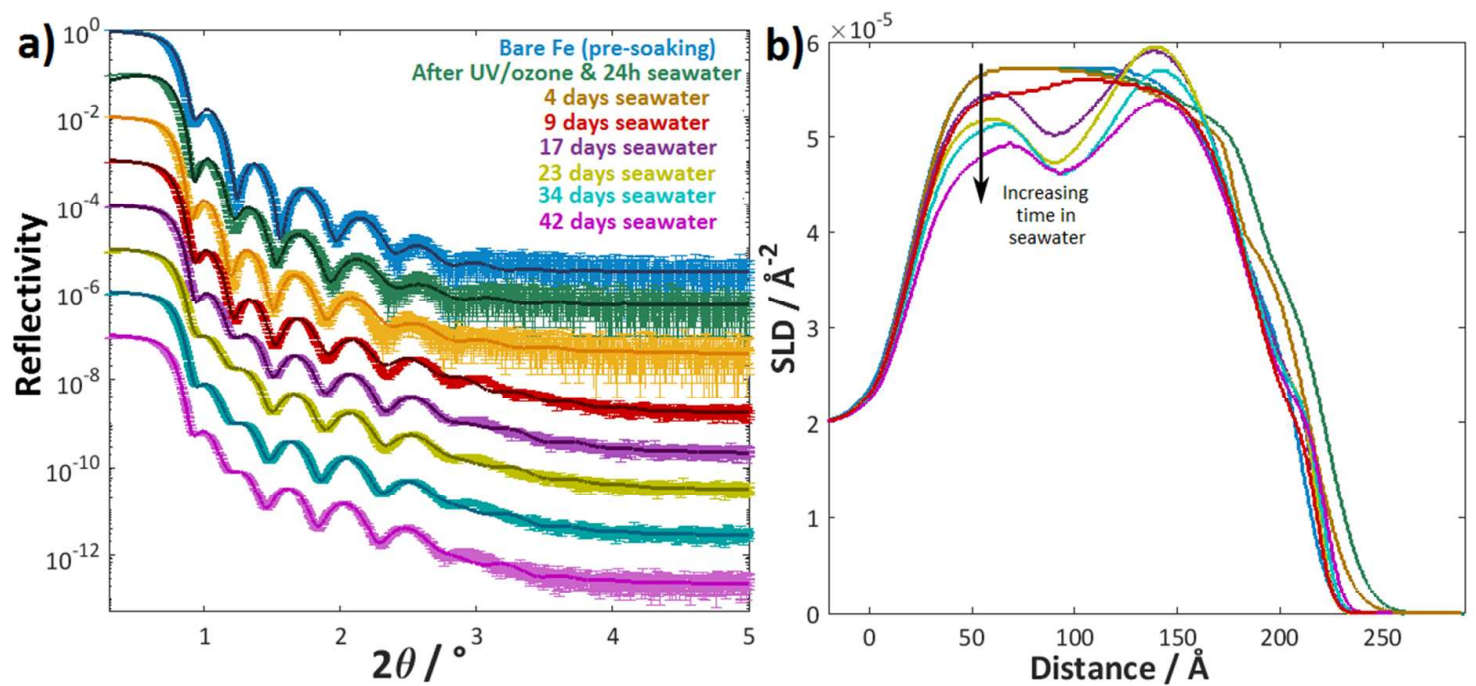

Figure 8a) XRR data (points) and model fits (solid lines) for an iron film as received and after cleaning by UV/ozone and then soaking in seawater for various amounts of time, as labelled. b) SLD profiles for the model fits.

A second sample was cleaned in the same way and its behaviour in seawater monitored over a longer timescale, with the results and model fits shown in Figure 8. The difference between this sample and the untreated iron samples soaked in seawater discussed above is immediately notable; whereas the untreated iron completely dissolved in under $24 \mathrm{~h}$, the sample cleaned by UV/ozone still retained most of the iron film even after 42 days, as can be seen in the continued observance of distinct fringes. From the SLD profiles generated by the model fits shown in Figure $8 \mathrm{~b}$, it can be seen that from 9-17 days onwards, a buried void structure begins to form (demonstrated by the dip in SLD). To obtain an acceptable fit, the sample had to be divided into several layers with high roughness. The void-presumed to arise from a loss of Fe caused by pitting corrosion-continued to grow until the end of the measurement at 42 days, and the iron layer decreased gradually in density.

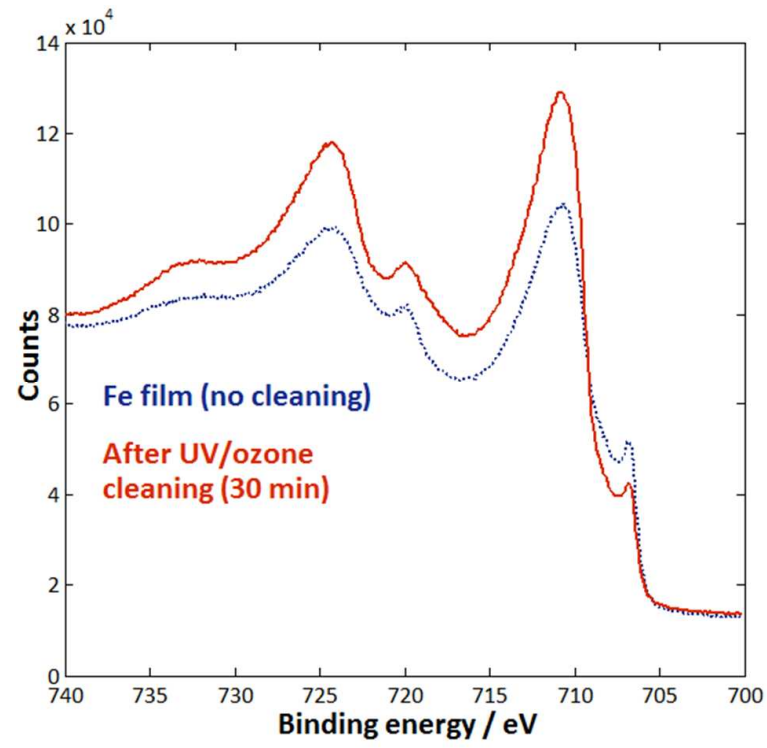

Figure 9. XPS spectra in the Fe $2 p$ region comparing an uncleaned Fe film (blue dotted line) to one cleaned by UV/ozone for $30 \mathrm{~min}$ (red solid line). 
Whilst the UV/ozone-grown oxide layer is clearly not entirely impermeable to water or dissolved corrosive ions, it still undoubtedly provides a much greater corrosion resistance than the untreated iron surface, even though this has a naturally-formed oxide layer of similar thickness. The effects of the UV/ozone cleaning on the surface are subtle in magnitude-only a small increase in oxide thickness and no difference seen in its density-but greatly increase the lifetime of the iron surface. One possible reason for this is that the native oxide may be patchy in places initially, and hence the UV/ozone treatment produces a full, unbroken layer with fewer reactive sites where corrosion may initialise. XPS spectra (Fe 2p region) for an as-deposited iron film with no cleaning compared to one cleaned by UV/ozone treatment (30 minutes) are shown in Figure 9. It is evident that the Fe metal $2 \mathrm{p}$ peak at $706.7 \mathrm{eV}$ diminishes after cleaning whilst the Fe oxides (encompassing both $\mathrm{Fe}^{\text {I" }}$ and $\mathrm{Fe}^{\mathrm{III}}$ ) $2 p_{3 / 2}$ peak around $711.0 \mathrm{eV}$ increases in intensity. The increase of oxide concentration at the surface would support the hypothesis of surface healing suggested by the XRR results.

As discussed in the introduction, several mechanisms remain in contention concerning the effect of the chloride ion on an iron oxide surface layer. Whilst no absolute conclusion can be inferred from the results here, it seems likely that a combination of mechanisms is indicated. Presumably, the primary effect of the UV/ozone cleaning is to heal any defects in the oxide film and ensure a complete, rather than patchy, oxide layer. This would support the film breakdown model as being the dominant initial pit formation mechanism. However, as pits do still form, although after a prolonged period of time, it may be that either the penetration and/or adsorption mechanisms come into force after a delay. Therefore, whilst UV/ozone cleaning is extremely effective at protecting the surface initially, further control measures may be needed to protect against these other mechanisms and eventual breakdown of the oxide film.

\section{(ii) Soaking in UPW}
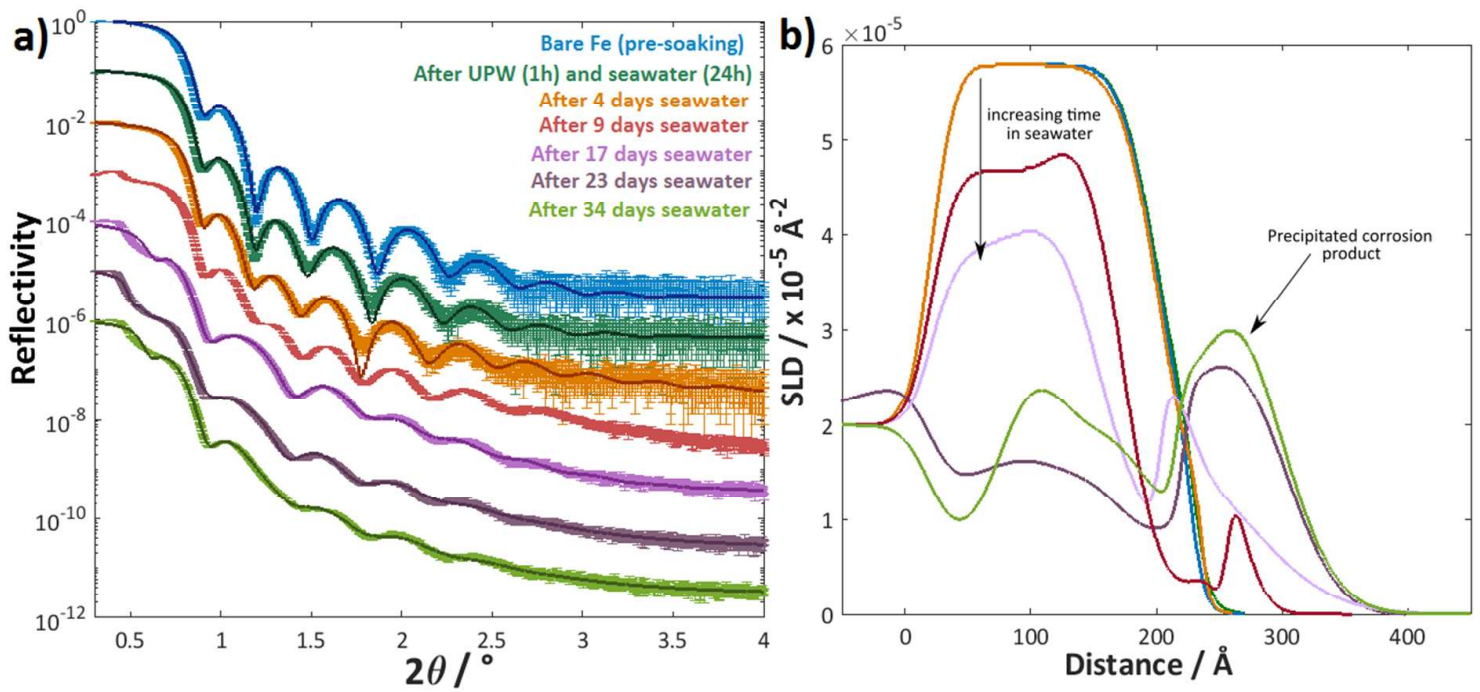

Figure 10a) XRR data (points) and model fits (solid lines) for an iron film as received and after soaking in UPW and then in seawater for various amounts of time, as labelled. b) SLD profiles for the model fits. 
Secondly, an iron film was soaked in UPW (18.2 $\mathrm{M} \Omega \mathrm{cm}$ resistivity) for one hour before then being soaked in seawater over varying amounts of time. The XRR data and model fits are shown in Figure 10. Surprisingly, the effect of pre-soaking the iron in UPW, even for only an hour, is seen to be highly efficacious in preventing corrosion, despite the sample being frequently dried and re-exposed to seawater afterwards. Whilst corrosion is seen to happen more quickly and more extensively than for the UV/ozone-cleaned sample shown above (Figure 8), the small fringes still seen after 34 days demonstrate that some kind of iron layer still remains, in distinct contrast to the unsoaked iron film that dissolves after $24 \mathrm{~h}$ (Figure 1). After 9 days, the fitted profile shows a thick precipitated corrosion layer at the surface (Figure 10b). However, the maintained good signal around the critical edge indicates that the sample is still reflective and that there hasn't therefore been extensive roughening.

There is no obvious immediate reason why this should happen; soaking a metal film in de-ionised water seems unlikely to grow a protective oxide layer or remove defects, although the model fit after $24 \mathrm{~h}$ in seawater (Figure 10b, green line) shows an increase of $5 \AA$ ( $\pm 3 \AA$ ) in the oxide thickness.

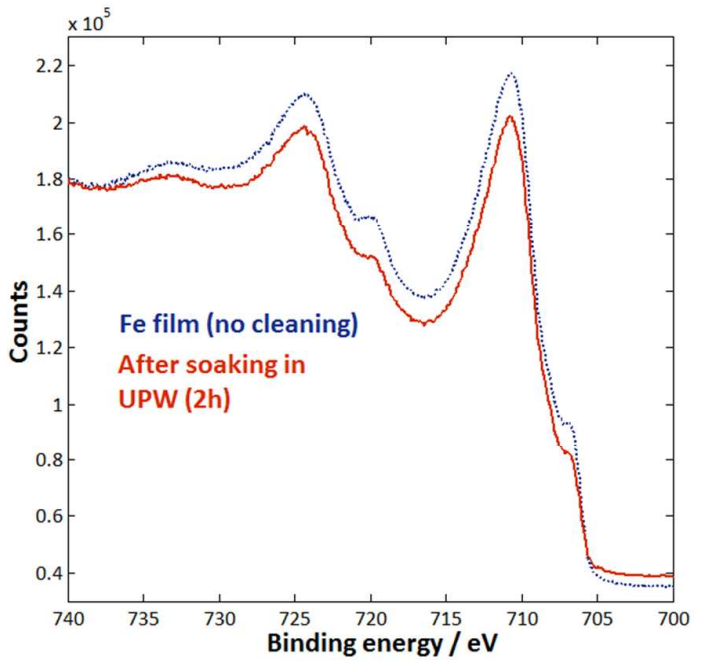

Figure 11. XPS spectra in the Fe $2 p$ region comparing an untreated Fe film (blue dotted line) to one soaked in UPW for 2 hours (red solid line).

In contrast to the XPS results for the UV/ozone-treated iron film (Figure 9), spectra comparing an uncleaned iron film to one soaked in UPW for 2 hours (Figure 11) show very little change in the peak intensity ratios, indicating that there has been no change in the nature or thickness of the passive layer. However, as shown by the XRR results, a film soaked for half this time showed a greatly enhanced corrosion resistance. Very little difference is seen in the deconvoluted peak fits for any of the regions analysed, shown in Figure S2 (C 1s, O 1s, Fe 3p, Fe 2p, Si 2p, Fe 3s and Si 2s). 


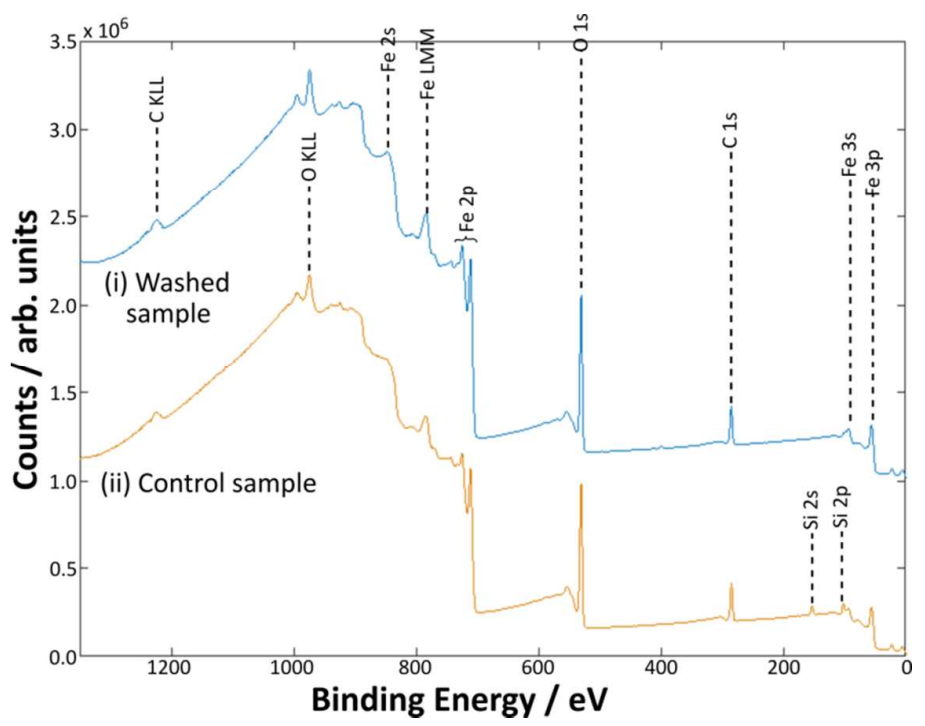

Figure 12. Survey XPS spectra for the untreated Fe film and that washed in UPW for $\mathbf{2} \mathrm{h}$, as labelled, with key peaks shown.

\begin{tabular}{|c|c|c|c|c|}
\hline \multirow{2}{*}{} & \multicolumn{2}{|c|}{ Control sample } & \multicolumn{2}{c|}{ UPW-soaked sample } \\
\cline { 2 - 5 } & $\begin{array}{c}\text { Binding } \\
\text { energy / eV }\end{array}$ & $\begin{array}{c}\text { Peak } \\
\text { Assignment }\end{array}$ & $\begin{array}{c}\text { Binding energy } \\
\text { / eV }\end{array}$ & $\begin{array}{c}\text { Peak } \\
\text { Assignment }\end{array}$ \\
\hline $\mathrm{Si} 2 \mathrm{p}^{50}$ & 101.7 & $\mathrm{Si}^{\prime \prime}$ or $\mathrm{Si}^{\text {III }}$ & 100.0 & $\mathrm{Si}^{0}$ \\
\hline $\mathrm{Si} 2 \mathrm{~s}$ & 153.2 & & $\mathrm{~N} / \mathrm{A}$ & \\
\hline $\mathrm{Fe} \mathrm{3s}$ & 93.6 & $\alpha-/ \mathrm{Fe}_{2} \mathrm{O}_{3}$ & 91.0 & $\mathrm{Fe}^{0} \mathrm{metal}$ \\
& & & 94.2 & $\mathrm{FeOOH}$ \\
\hline $\mathrm{Fe} \mathrm{3p}$ & 52.8 & $\mathrm{Fe}^{0}$ metal & 52.6 & $\mathrm{Fe}^{0}$ metal \\
& 55.7 & $\alpha-/ \mathrm{Fe}_{2} \mathrm{O}_{3}$ & 55.4 & $\alpha-/ \mathrm{Fe}_{2} \mathrm{O}_{3}$ \\
\hline
\end{tabular}

Table 3. XPS fitted parameters for the Si $2 s$ and $2 p$ and the Fe $3 s$ and $3 p$ peaks for control iron film and that washed in UPW.

The survey spectra for an untreated iron film (freshly deposited) and that washed in UPW are shown in Figure 12. The only significant difference is that the control sample shows a small peak for the silicon $2 s$ region, which is missing in the washed sample. The fits for the Si peaks and Fe $3 s$ and $3 p$ peaks (which give the clearest distinction between the different Fe oxides) are summarised in Table 3; the Fe $3 p$ spectra for both suggest the dominant species is Fe"l oxide rather than Fe" (which would show a peak closer to $54.0 \mathrm{eV}^{51}$. This is supported by the Fe $2 \mathrm{p}$ spectra, which were deconvoluted into peaks at 711 and $713 \mathrm{eV}$ for both samples, indicative of the $\mathrm{Fe}^{\mathrm{III}} 2 \mathrm{p}_{3 / 2}$ peak and its satellite (whereas the binding energy for $\mathrm{Fe}^{\prime \prime}$ is expected to occur around 709-710 eV). The Fe 3s peak for the sample washed in UPW may also indicate the presence of $\mathrm{FeOOH}$. 
There is a subtle difference in the Si $2 p$ assignments for the two samples, although this is complicated due to their proximity to the Fe 3s peaks; the main difference is seen in the $2 \mathrm{~s}$ region, where a significant peak is seen for the untreated iron surface but no peak seen for that washed in UPW (peak fits shown in Figure S2). The peak for the untreated surface at $153.2 \mathrm{eV}$ is indicative of a silicon salt, perhaps an organosilicate. It seems unlikely that this could have an effect on the rate of corrosion, however, and certainly not to the extent seen here. Therefore, the only conclusion must be that the water interacts with the iron oxide surface in some way that is not detectable by XPS but that considerably enhances its resistance to corrosion. One potential explanation may be that there is some kind of subtle but significant change in the surface segregation of the Fe ions ( $\mathrm{Fe}^{\text {"I }}$ vs $\mathrm{Fe}^{\text {III})}$ that falls within the thickness sampled by the XPS and hence cannot be easily resolved. However, this is supposition and cannot be directly inferred from these results.

(2) Effect of corrosion inhibitors

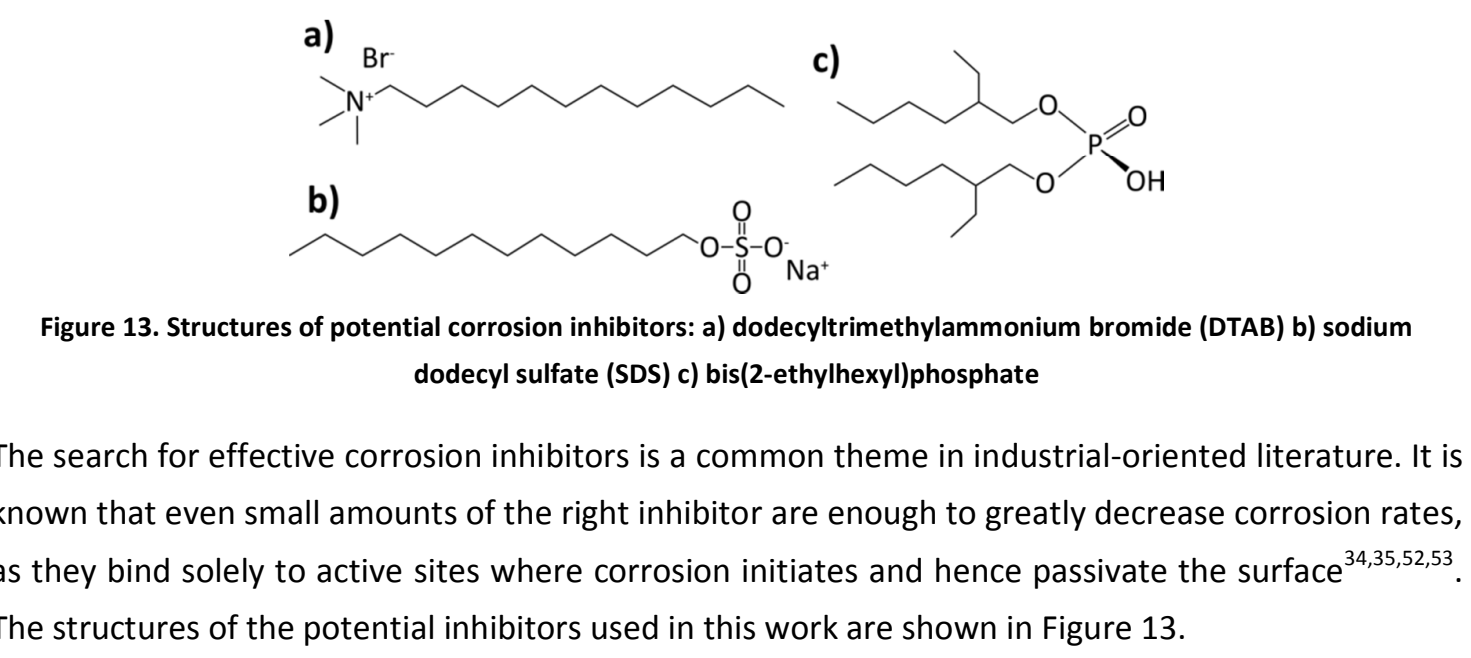

(i) Dodecyltrimethylammonium bromide (DTAB) 

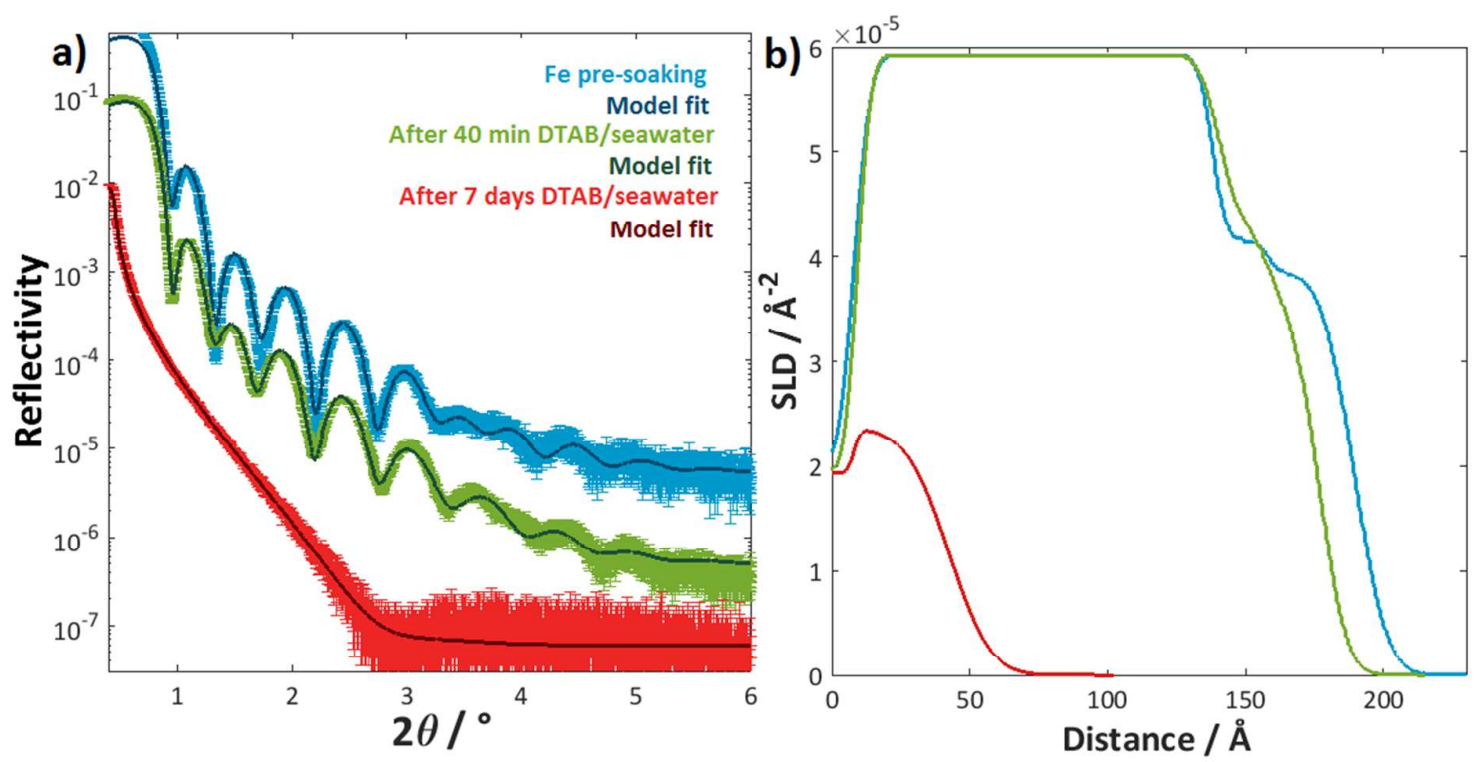

Figure 14a) XRR data (points) and model fits (solid lines) for an iron film as-deposited and then after $\mathbf{4 0}$ min and $\mathbf{7}$ days soaking in a DTAB/seawater solution, as labelled. Data transposed vertically for clarity. b) SLD profiles for the model fits.

From consideration purely of electrostatic effects, it might be supposed that DTAB should have the strongest corrosion inhibition effect; the isoelectric point (IEP) of iron oxide is generally recorded as lying between $\mathrm{pH} 6.0$ and $8.0^{54-56}$ (zeta-potential results further indicate this is lowered to $6.2(\underline{+0.5})$ in $\mathrm{NaCl}$ solutions) and so the surface should be negatively-charged at the $\mathrm{pH}$ of seawater $\left(7.5-8.5^{57}\right)$. Hence, the cationic DTAB might be expected to adsorb to the anionic surface and so act as an inhibitor.

However, as seen in Figure 14, no such corrosion inhibition is seen; indeed, there is significant roughening of the iron surface after just 40 minutes, suggesting early breakdown of the oxide film. Wei et al. also surmise that the positively-charge DTAB will prefer to bind at different surface sites to the negatively-charged chloride anion and hence have little effect on the rate at which they attack the metal ${ }^{58}$. A negatively-charged surfactant that adsorbs strongly should be able to compete with, and possibly displace, the chloride ion, resulting in a reduced corrosion rate. We now consider two anionic surfactants.

(ii) Sodium dodecyl sulfate (SDS) 

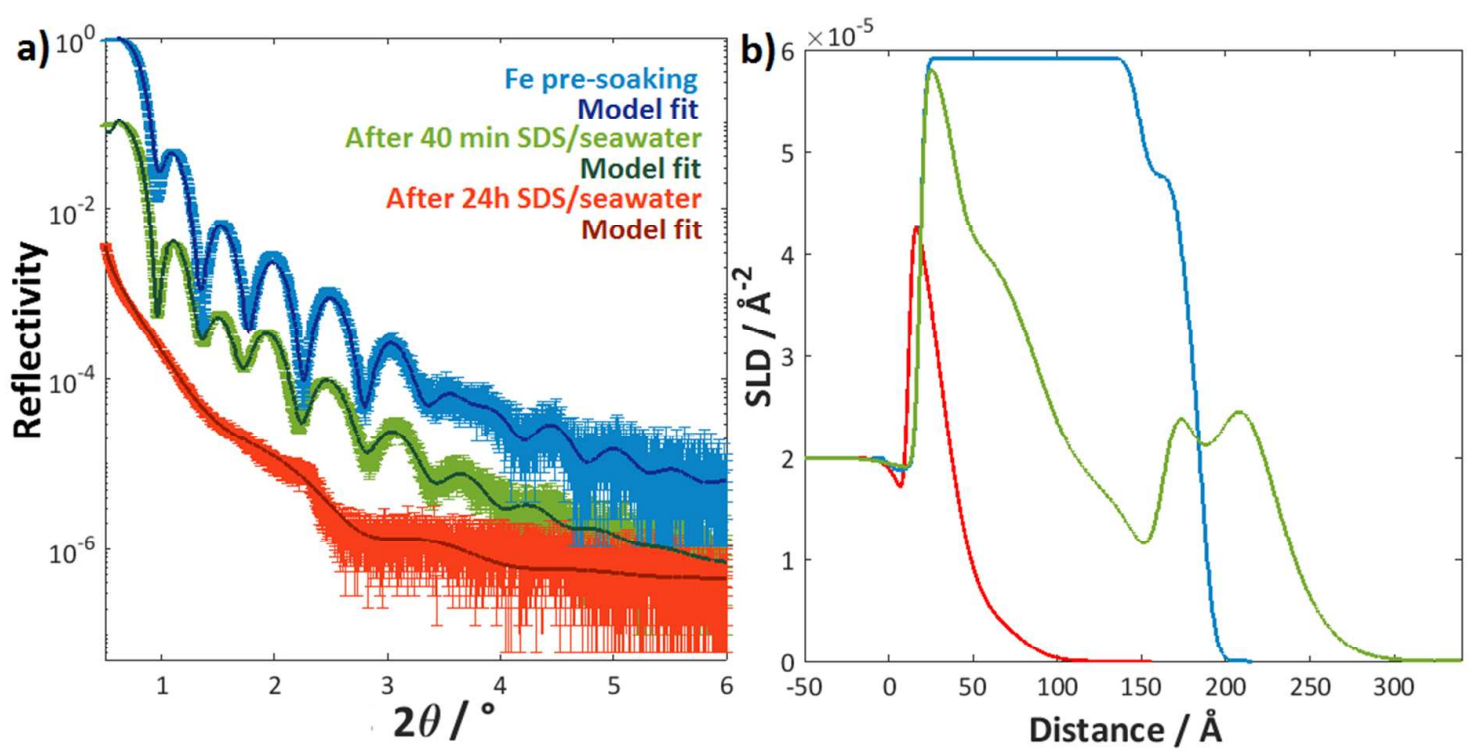

Figure 15a) XRR data (points) and model fits (solid lines) for an iron film as-deposited and then after $40 \mathrm{~min}$ and $24 \mathrm{~h}$ soaking in a SDS/seawater solution, as labelled. Data transposed vertically for clarity. b) SLD profiles for the model fits.

Two negatively-charged surfactants were studied-SDS and bis(2-ethylhexyl)phosphate. The results for SDS are shown in Figure 15; it is evident that there is no improvement in corrosion inhibition over $24 \mathrm{~h}$, and indeed the surface seems to be significantly corroded after only 40 minutes. SDS is known to work as an effective corrosion inhibitor for metals in acidic environments, presumably due to the electrostatic attraction to the positively-charged surface at low $\mathrm{pH}^{35}$; however, sulfate anions have been reported to have a catalytic effect on iron dissolution due to the formation of an intermediate $\mathrm{FeSO}_{4}{ }^{+}$complex that is more soluble than the $\mathrm{Fe}^{\text {III }}$ ion ${ }^{59}$. It would seem likely that something similar occurs in this situation with the $\mathrm{RSO}_{4}{ }^{-}$headgroup aiding dissolution of the metal cations, and hence leading to an increased rate of corrosion.

(iii) Bis(2-ethylhexyl)phosphate 

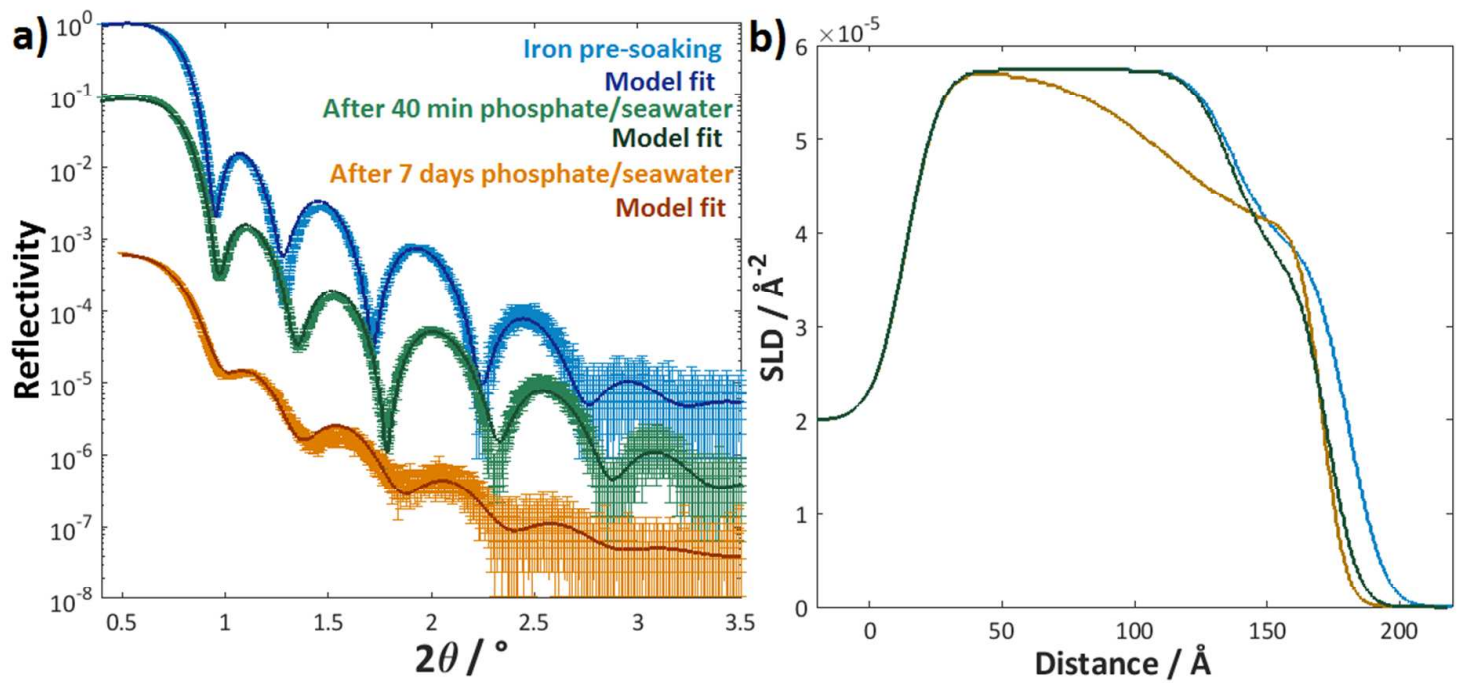

Figure 16a) Fitted XRR data for the iron film pre- and post-exposure to phosphate/seawater, as labelled, with model fits b) Corresponding SLD profiles.
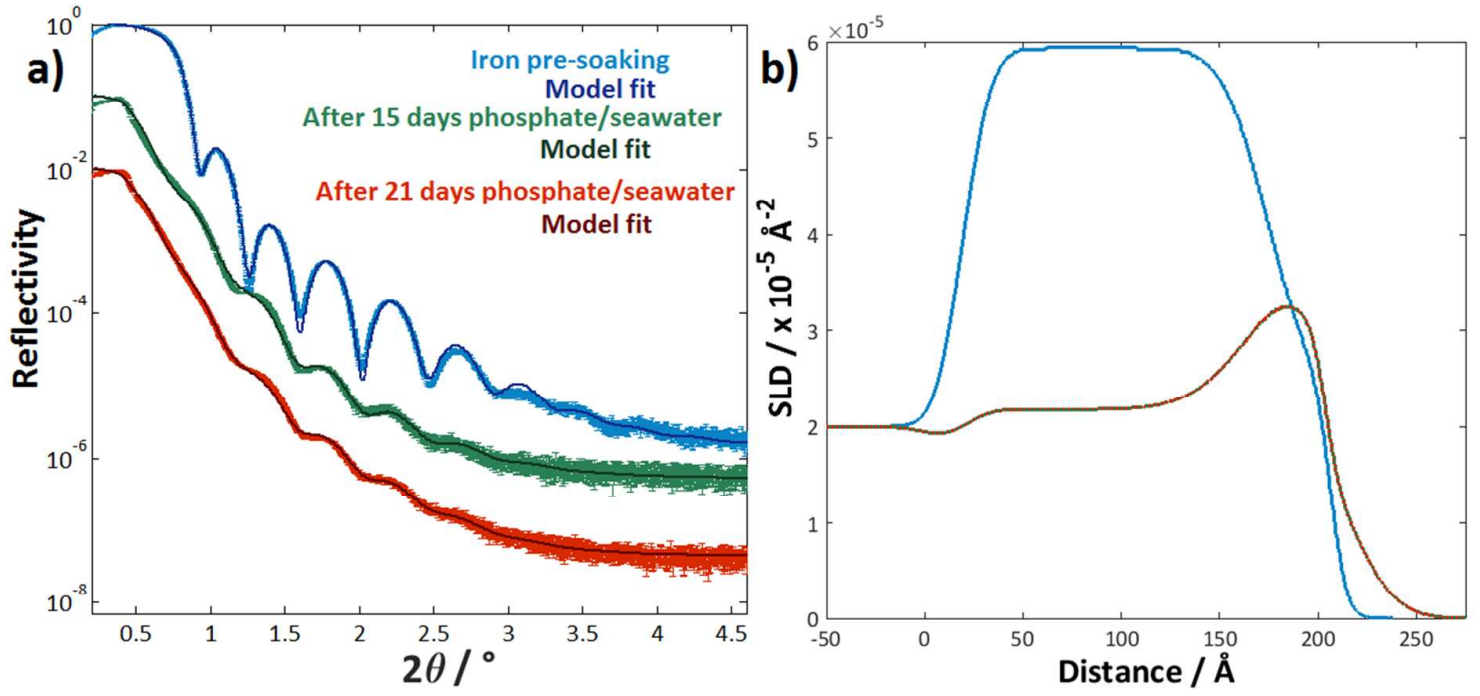

Figure 17. a) Fitted XRR data for the iron film pre- and post-exposure to phosphate/seawater, as labelled, with model fits b) Corresponding SLD profiles.

Two samples were soaked in a saturated phosphate solution (bis(2-ethylhexyl)phosphate) in seawater over varying lengths of time, as shown in Figure 16. The phosphate does not completely halt corrosion; over 7 days, significant roughening of the surface is seen (the roughness of the iron layer increases from 12 to $32 \AA$ ), presumably due to patches of the iron corroding more quickly than other areas. However, this is a significant improvement on having no inhibitor, and better than the results seen for SDS and DTAB. Furthermore, after 15-21 days (Figure 17), a film of around the same thickness as the starting iron film is still observed, but with a density (and hence SLD) that is around a third of that expected for bulk Fe. This could be caused by patches of dissolution leading to an average decrease in density across a maintained thickness, or possibly by ingress of an element with lower SLD (such as $\mathrm{O}$ or $\mathrm{C}$ ) into the iron layer. 


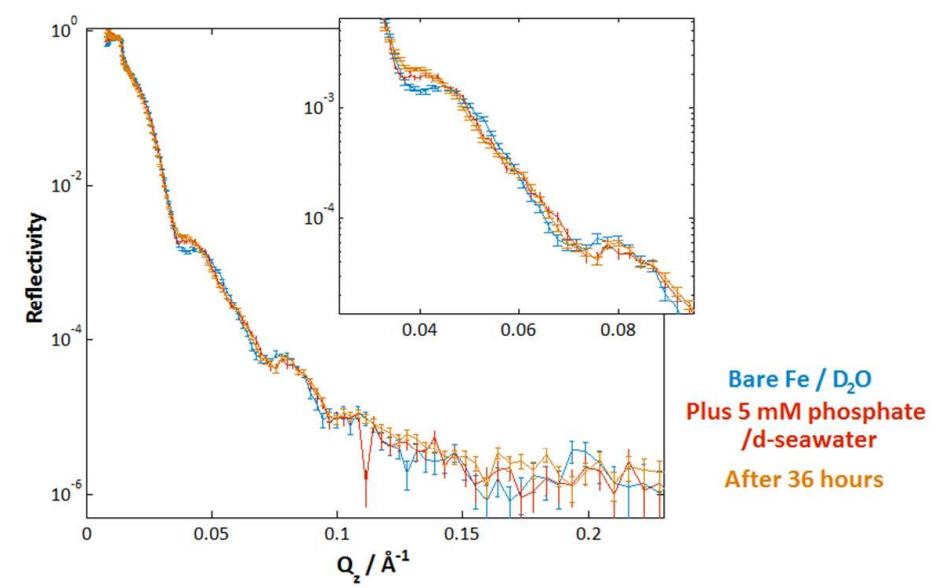

Figure 18. Raw NR data for a bare iron film and after soaking in the phosphate/ $D_{2} O$-seawater solution, immediately and after $36 \mathrm{~h}$, as labelled.
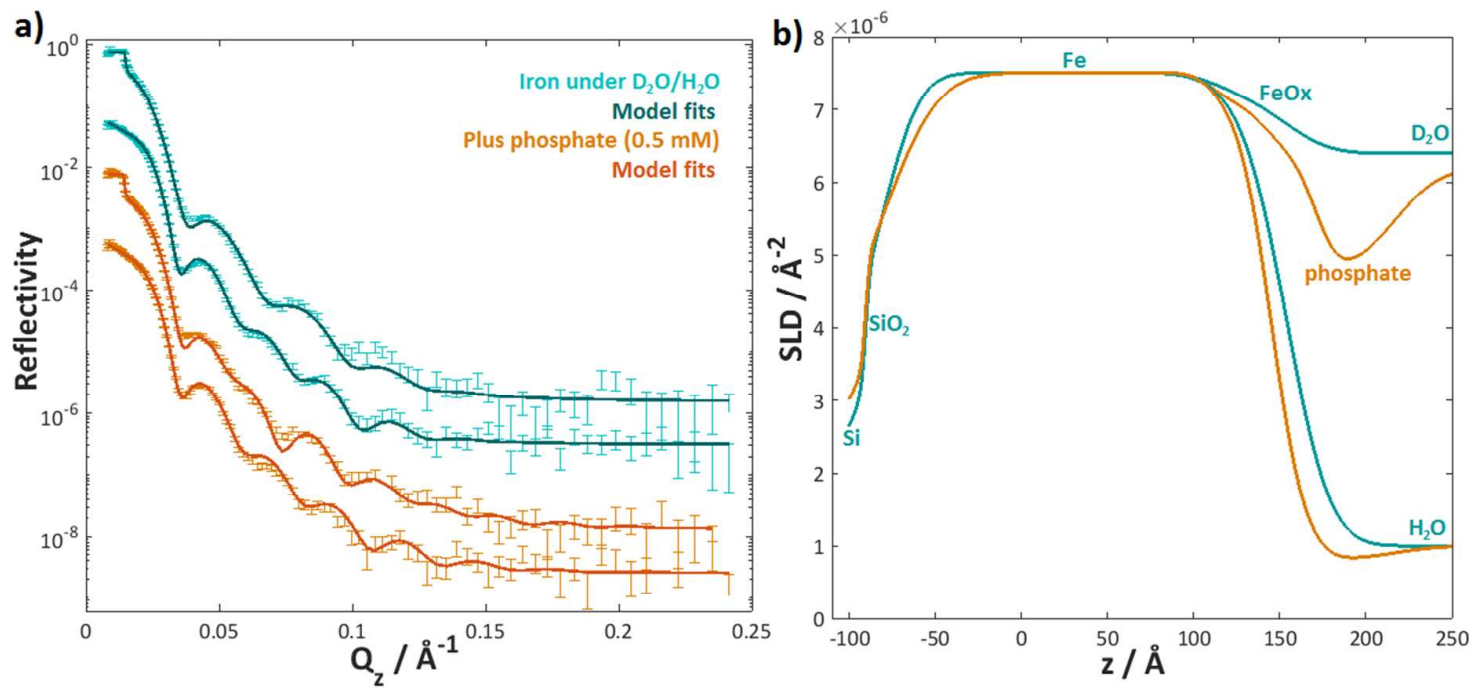

Figure 19a) NR data for the bare iron surface (blue) under $\mathrm{D}_{2} \mathrm{O}$ and $\mathrm{H}_{2} \mathrm{O}$ and plus bis(2-ethylhexyl)phosphate (orange), saturated solution in $\mathrm{D}_{2} \mathrm{O}$-seawater and $\mathrm{H}_{2} \mathrm{O}$-seawater in order of descent. Data offset vertically for clarity. Data shown as points and model fits as solid lines. b) SLD profiles corresponding to the model fits.

An iron film pre- and post-soaking in a phosphate/seawater solution was also examined using neutron reflectometry; raw data for the bare iron film in $\mathrm{D}_{2} \mathrm{O}$, after the addition of the phosphate in $\mathrm{D}_{2} \mathrm{O}$-seawater and measured again after $36 \mathrm{~h}$ are shown in Figure 18. Qualitatively, it is clear that an adsorbed layer has formed after immersion in the phosphate-containing solution, seen by the decrease in fringe spacing. However, the changes are relatively subtle, indicating that the film is diffuse. After $36 \mathrm{~h}$, no change is seen in the reflectivity profiles, implying that no metal corrosion has occurred (also inferred from visual inspection of the sample, which looked unchanged). Model fits for the bare iron surface and the phosphate adsorption are shown in Figure 19. The bare sample comprised an iron layer $195 \AA$ ( $\pm 3 \AA$ ) thick and an oxide layer $39 \AA$ ( $\pm 3 \AA$ ) thick. After addition of the phosphate, inclusion of a $45 \AA$ ( $\pm 5 \AA$ ) phosphate layer, 77 \% hydrated (i.e. $77 \%$ of the surfactant layer was water), was needed to model the data. 
Whilst it may appear surprising that the negatively-charged phosphate binds at all to the negativelycharged surface (at this $\mathrm{pH}$ ), the low coverage ( $23 \%$ ) indicates that the phosphate is selectively binding to a few surface sites-presumably the positively-charged anode sites. As this is where the chloride ions preferentially attack and hence where corrosion is initiated, selective adsorption of the phosphate to these sites has a significantly passivating effect. Although the overall surface charge is negative, the relatively high cation concentration in the seawater solution allows the phosphate to approach the surface. This may simply arise from the very strong 'screening' at the high electrolyte concentrations or potentially a cation-bridging effect, which has been observed previously for several systems ${ }^{60-62}$, including phosphates binding to negatively-charged silica hydroxyl surfaces ${ }^{63}$. The relative insolubility of the phosphate also makes it unlikely that it will complex the iron ions into solution as the SDS seems to do.

Both organic and inorganic phosphates are commonly-used as corrosion inhibitors for steel surfaces in a range of environments ${ }^{64,65}$; although the results shown here indicate their effect is not as powerful as the surface-treatment approaches outlined above, they are clearly still able to exert a protective influence on the iron surface over a short amount of time, and hence to use them in conjunction with a rigorous surface preparation may be extremely valuable.

\section{Conclusions}

X-ray reflectometry has been used to monitor the dissolution of a deposited iron film when soaked in artificial seawater, showing average void growth under the passive oxide film from around 3 hours onwards that we interpret as arising from pitting corrosion. The entirety of a $20 \mathrm{~nm}$ iron film was completely dissolved between around 15 and 24 hours, with only a little iron-containing material remaining.

Interestingly, it was found that two very simple treatment steps were highly effective in delaying this corrosion for several weeks; first, cleaning the samples by UV/ozone for only a short amount of time rendered the iron film intact for around 10 days, although a void did develop after this time. Although XRR results showed only a small growth in the oxide film thickness, the XPS signal ratio for the oxide to metal increased, indicating perhaps that any defects in the oxide had been repaired. This could account for the significant delay in corrosion onset.

Secondly, soaking the samples in UPW for an hour before exposure to seawater was also surprisingly effective in preventing corrosion, albeit to a lesser extent than the UV/ozone cleaning. As neither the XRR nor XPS results comparing the as-deposited and soaked films showed any notable differences, it is unclear how this effect arises.

Whilst no conclusion can be drawn from these results about the mechanism of chloride-assisted corrosion, they may add slightly greater weight to the film break mechanism as being the dominant 
initial mechanism rather than adsorption or penetration, since no significant increase in oxide thickness was observed for the UV/ozone cleaning, but rather the corrosion protection effect was presumed to arise from healing of defects in the oxide film. The eventual void formation in even the UV/ozone-cleaned films indicates that other corrosion mechanisms may also be occurring but with a delayed onset.

Finally, the effects of three potential corrosion inhibitors were studied. Neither DTAB nor SDS offered any improvement to the protection of the metal surface-indeed, SDS even seemed to accelerate the metal dissolution, presumably by catalysing dissolution of the insoluble $\mathrm{Fe}^{\mathrm{III}}$ ions. However, bis(2-ethylhexyl)phosphate was able to protect the surface, with only two thirds of the metal film dissolved after 21 days in seawater. The NR results showed formation of a relatively thick but diffuse surfactant layer bound to the iron oxide surface. The negatively-charged phosphate anion is likely to bind selectively to anode surface sites where corrosion will preferentially initiate via chloride attack. As the phosphate is less soluble than SDS and binds less strongly, it is less likely to catalyse dissolution of the metal cations.

\section{Acknowledgements}

With thanks to Shell for funding this work, and in particular to Dr Lene Hviid and Dr Ron van Tol for supporting the project. We thank Juan Rubio-Lara (Nanoscience, University of Cambridge) for the thin film depositions. The neutron reflectivity data were collected using the Offspec instrument at the ISIS facility, Rutherford Appleton Laboratory (RB number 1710233, doi: 10.5286/ISIS.E.84794399). X-ray photoelectron spectra were collected at the National Engineering and Physical Sciences Research Council (EPSRC) XPS User's Service (NEXUS) at Newcastle University, an EPSRC mid-range facility.

Supporting Information. Photographs of iron film/silicon substrate taken before and after various stages of soaking in seawater. Detailed XPS for the iron film pre- and post-soaking in UPW. Explanation of the bespoke bootstrapping error analysis procedure, with examples provided.

\section{Bibliography}

(1) Mills, A.; Hazafy, D. UV-activated photocatalyst films and inks for cleaning tarnished metals. Chem. Commun. 2012, 48, 525-527.

(2) Noël, J. J. In Neutron reflectometry-a probe for materials Surfaces; International Atomic Energy Agency, 2004; pp 79-84.

(3) Jones, D. A. Principles and Prevention of Corrosion; Prentice-Hall, Inc.: New Jersey, 1992.

(4) McCafferty, E. Introduction to corrosion science; Springer Science \& Business Media: USA, 2010.

(5) Scully, J. C. The fundamentals of corrosion; Pergamon press: Oxford, 1990.

(6) Frankel, G. S. Pitting corrosion of metals. J. Electrochem. Soc. 1998, 145, 2186-2198.

(7) Soltis, J. Passivity breakdown, pit iniation and propagation of pits in metallic materials. Corr. Sci. 2015, 90, 5-22.

(8) Kolotyrkin, J. Pitting corrosion of metals. Corrosion 1963, 19, 261t-268t. 
(9) Szklarska-Smialowska, Z. Review of literature on pitting corrosion published since 1960. Corrosion 1971, 27, 223-233.

(10) Strehblow, H.-H. In Corrosion mechanisms in theory and practice; Marcus, P., Ed.; Marcel Dekker, Inc.: New York, 2002.

(11) Heusler, K. E.; Fischer, L. Kinetics of pit iniation at passive iron. Werkst. Korros. 1976, 27, 551556.

(12) Hoar, T. P.; Jacob, W. R. Breakdown of passivity of stainless steels by halide ions. Nature 1967, 216, 1299-1301.

(13) Evans, U. R. The passivity of metals. Part 1. The isolation of the protective film. J. Chem. Soc. 1927, 0, 1020-1040.

(14) Bardwell, J. A.; MacDougall, B. Pitting of iron by chloride in borate buffer solution. J. Electrochem. Soc. 1988, 135, 2157-2161.

(15) Bardwell, J. A.; Macdougall, B. Involvement of surface oxide films on iron in halide-induced pitting. Electrochim. Acta 1989, 34, 229-232.

(16) Fushimi, K.; Seo, M. Initiation of a local breakdown of passive film on iron due to chloride ions generated by a liquid-phase ion gun. J. Electrochem. Soc. 2001, 148, B450-B456.

(17) Sato, N. A theory for breakdown of anodic oxide films on metals. Electrochim. Acta 1971, 16, 1683-1692.

(18) Pou, T. E.; Murphy, O. J.; Young, V.; Bockris, J. O. M.; Tongson, L. L. Passive films on iron: the mechanism of breakdown in chloride containing solutions. J. Electrochem. Soc. 1984, 131, 1243-1251.

(19) Rosenfeld, I. L.; Danilov, I. S. Electrochemical aspects of pitting corrosion. Corr. Sci. 1967, 7, 129-142.

(20) Kruger, J.; Long, G. G.; Kuriyama, M.; Goldman, A. I. In Proceedings of the 5th international symposium on passivity.; Froment, M., Ed.; 1983; $p 163$.

(21) MacDougall, B.; Mitchell, D. F.; Sproule, G. I.; Graham, M. J. Incorporation of chloride ion in passive oxide films on nickel. J. Electrochem. Soc. 1983, 130, 543-547.

(22) Atanasoska, L. D.; Dražić, D. M.; Despić, A. R.; Zalar, A. Chloride ion penetration into oxide films on aluminium Auger and XPS studies. J. Electroanal. Chem. 1985, 182, 179-186.

(23) Goetz, R.; MacDougall, B.; Graham, M. J. An AES and SIMS study of the influence of chloride on the passive oxide film on iron. Electrochim. Acta 1986, 31, 1299-1303.

(24) Khalil, W.; Haupt, S.; Strehblow, H. -H. The thinning of the passive layer of iron by halides. Werkst. Korros. 1985, 36, 16-21.

(25) Szklarska-Smialowska, Z.; Viefhaus, H.; Janik-Czachor, M. Electron spectroscopy analysis of indepth profiles of passive films formed on iron in Cl-containing solution. Corr. Sci. 1976, 16, 14.

(26) Mischler, S.; Vogel, A.; Mathieu, H. J.; Landolt, D. The chemical composition of the passive film on Fe-24Cr and Fe-24Cr-11Mo studied by AES, XPS and SIMS. Corr. Sci. 1991, 32, 925944.

(27) Strehblow, H. -H. In Corrosion mechanisms in theory and practice; Marcus, P., Oudar, J., Eds.; Marcel Dekker, Inc.: New York, 1995.

(28) Konno, H.; Nagayama, M. X-ray photoelectron spectra of hexavalent iron. J. Electron Spectrosc. Rel. Phenom. 1980, 18, 341-343.

(29) Wood, M. H.; Welbourn, R. J. L.; Charlton, T.; Zarbakhsh, A.; Casford, M. T.; Clarke, S. M. Hexadecylamine adsorption at the iron oxide-oil interface. Langmuir 2013, 29, 13735-13742.

(30) Kruger, J.; Krebs, L. A.; Long, G. G.; Anker, J. F.; Majkrzak, C. F. Passivity of metals and alloys and its breakdown - new results from new non-electrochemical techniques. Mater. Sci. Forum 1995, 185-188, 367-376.

(31) Haupt, S.; Strehblow, H. H. Corrosion, layer formation and oxide reduction of passive iron in alkaline solution: a combined electrochemical and surface analytical study. Langmuir 1987, 3, 873-885. 
(32) Cahan, B. D.; Chen, C.-T. The nature of the passive film on iron. I. Automatic ellipsometric spectroscopy studies. J. Electrochem. Soc. 1982, 129, 921-925.

(33) Foley, C. L.; Kruger, J.; Bechtold, C. J. Electron diffraction studies of active passive and transpassive oxide films formed on iron. J. Electrochem. Soc. 1967, 114, 994-1001.

(34) Nii, K. On the dissolution behaviour of NiO. Corr. Sci. 1970, 10, 571-583.

(35) Wood, M. H.; Welbourn, R. J. L.; Zarbakhsh, A.; Gutfreund, P.; Clarke, S. M. Polarised neutron reflectometry of nickel corrosion inhibitors. Langmuir 2015, 31, 7062-7072.

(36) Welbourn, R. J. L.; Truscott, C. L.; Skoda, M. W. A.; Zarbakhsh, A.; Clarke, S. M. Corrosion and inhibition of copper in hydrocarbon solution on a molecular level investigated using neutron reflectometry and XPS. Corr. Sci. 2017, 115, 68-77.

(37) Morales-Gil, P.; Walczak, M. S.; Cottis, R. A.; Romero, J. M.; Lindsay, R. Corrosion inhibitor binding in an acidic medium: interaction of 2-mercaptobenizmidazole with carbon-steel in hydrochloric acid. Corr. Sci. 2014, 85, 109-114.

(38) Kobe, B. A.; Ramamurthy, S.; Biesinger, M. C.; Mclntyre, N. S.; Brennenstühl, A. M. XPS imaging investigations of pitting corrosion mechanisms in Inconel 600. Surf. Int. Anal. 2005, 37, 478-494.

(39) Qiu, J. H.; Chua, P. H. EIS and XPS study of the corrosion of carbon steel in inhibited natural seawater. Surf. Int. Anal. 1999, 28, 119-122.

(40) Wood, M. H.; Clarke, S. M. Neutron reflectometry for studying corrosion and corrosion inhibition. Metals. 2017, 7, 304.

(41) Springell, R.; Rennie, S.; Costelle, L.; Darnbrough, J.; Stitt, C.; Cocklin, E.; Lucas, C.; Burrows, R.; Sims, H.; Wermeille, D.; Rawle, J.; Nicklin, C.; Nuttall, W.; Scott, T.; Lander, G. Water corrosion of spent nuclear fuel: radiolysis driven dissolution at the $\mathrm{UO}_{2} /$ water interface. Faraday Discuss. 2015, 180, 301-311.

(42) Kester, D. R.; Duedall, I. W.; Connors, D. N.; Pytkowicz, R. M. Preparation of artificial seawater. Limnol. Ocean. 1967, 12, 176-179.

(43) Berges, J. A.; Franklin, D. J.; Harrison, P. J. Evolution of an artificial seawater medium: improvements in enriched seawater, artificial water over the last two decades. J. Phycol. 2001, 37, 1138-1145.

(44) Björck, M.; Andersson, G. GenX: an extensible X-ray reflectivity refinement program utilising differential evolution. J. Appl. Cryst. 2007, 40, 1174-1178.

(45) Charlton, T. R.; S, C. R. L.; M, D. R.; Kinane, C. J.; Neylon, C.; Langridge, S.; Plomp, J.; Webb, N. G. J.; Webster, J. R. P. Advances in neutron reflectometry at ISIS. Neutron News 2011, 22, 15 18.

(46) Isaacs, H. S.; Kissel, G. Surface preparation and pit propagation in stainless steels. J. Electrochem. Soc. 1972, 119, 1628-1632.

(47) Jüttner, K. Electrochemical impedance spectroscopy (EIS) of corrosion processes on inhomogeneous surfaces. Electrochim. Acta 1990, 35, 1501-1508.

(48) Singh, S.; Basu, S.; Poswal, A. K. K.; Tokas, R. B. B.; Ghosh, S. K. K. Electrochemically controlled pitting corrosio in Ni film: a study of AFM and neutron reflectometry. Corr. Sci. 2009, 51, 575580 .

(49) Singh, R. Corrosion control for offshore structures; Elsevier Inc.: USA, 2014.

(50) Himpsel, F. J.; McFeely, F. R.; Taleb-Ibrahimi, A.; Yarmoff, J. A.; Hollinger, G. Microscopic structure of the $\mathrm{SiO}_{2} / \mathrm{Si}$ interface. Phys. Rev. B 1988, 38, 6084-6096.

(51) Mclntyre, N. S.; Zetaruk, D. G. X-ray photoelectron spectroscopic studies of iron oxides. Anal. Chem. 1977, 49, 1521-1529.

(52) Khalifa, D. R.; Abdallah, S. M. Corrosion inhibition of some organic compounds on low carbon steel in hydrochloric acid solution. Port. Electrochim. Acta 2011, 29, 47-56.

(53) Kuznetsov, Y. I.; Mercer, A. D.; Thomas, J. G. N. Organic Inhibitors of Corrosion of Metals; Springer US: USA, 1996.

(54) Iwasaki, I.; Cooke, S. R. B.; Kim, Y. S. Some surface properties and flotation characteristics of 
magnetite. Trans. AIME 1962, 223, 113-120.

(55) Parks, G. A. Isoelectric points of solid oxides, solid hydroxides and aqueous hydroxo complex systems. Chem. Rev. 1965, 65, 182-198.

(56) Hsi, C. D.; Langmuir, D. Adsorption of uranyl onto ferric oxohydroxides: application of the surface complexation site-binding model. Geochim. Cosmochim. Acta 1985, 49, 1931-1941.

(57) Marion, G. M.; Millero, F. J.; Camões, M. F.; Spitzer, P.; Feistel, R.; Chen, C. A. pH of seawater. Mar. Chem. 2011, 126, 89-96.

(58) Wei, Z.; Somasundaran, P.; Duby, P. Pitting inhibition by surfactants. J. Electrochem. Soc. 2004, 151, B304-B308.

(59) Vetter, K. J.; Gorn, F. Kinetics of layer formation and corrosion processes of passive iron acid solutions. Electrochim. Acta 1973, 18, 321-326.

(60) Wang, X.; Lee, S. Y.; Miller, K.; Stocker, I.; Clarke, S.; Casford, M.; Gutfreund, P.; Skoda, M. W. A. Cation bridging studied by specular neutron reflection. Langmuir 2013, 29, 5520-5527.

(61) Aquino, L. I. A. J. A.; Tunega, D.; Schaumann, G. E.; Haberhauer, G.; Gerzabek, M. H.; Lischka, $\mathrm{H}$. The functionality of cation bridges for binding polar groups in soil aggregates. Int. J. Quantum Chem. 2011, 111, 1531-1542.

(62) Allen, F. J.; Griffin, L. R.; Alloway, R. M.; Gutfreund, P.; Lee, S. Y.; Truscott, C. L.; Welbourn, R. J. L.; Wood, M. H.; Clarke, S. M. An anionic surfactant on an anionic substrate: monovalent cation binding. Langmuir 2017, 33, 7881-7888.

(63) Murashov, V. V.; Leszczynski, J. Adsorption of the phosphate groups on silica hydroxyls: an ab initio study. J. Phys. Chem. A 1999, 103, 1228-1238.

(64) Naraghi, A.; Grahmann, N. Corrosion inhibitor blends with phosphate esters. U.S. Patent No. 5.611.992, 1997.

(65) Uhlig, H. H.; Triadis, D. N.; Stern, M. Effect of oxygen, chlorides and calcium ion on corrosion inhibition of iron by polyphosphates. J. Electrochem. Soc. 1955, 102, 59-66. 
TOC Graphic:

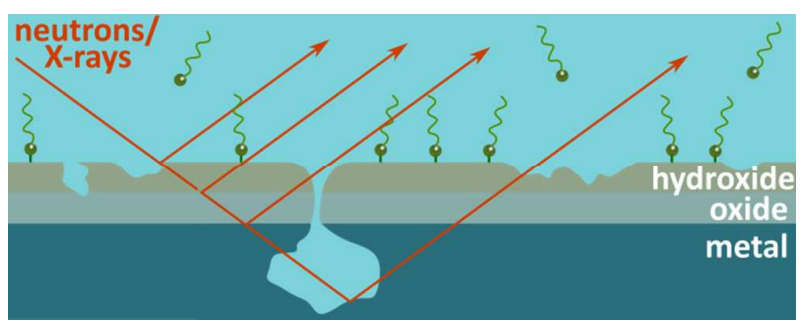

